1

\title{
Perspectives and challenges associated with the determination of new psychoactive substances in urine and wastewater - A Tutorial
}

\author{
L. Bijlsma ${ }^{a *}$, R. Bade ${ }^{b^{*}}$, F. Been ${ }^{c}$, A. Celma ${ }^{a}$, S. Castiglionid
}

a Environmental and Public Health Analytical Chemistry, Research Institute for Pesticides and Water, University Jaume I, 12071 Castellón, Spain

${ }^{b}$ University of South Australia, UniSA: Clinical and Health Sciences, Health and Biomedical Innovation, South Australia 5000, Australia

c KWR Water Research Institute, Chemical Water Quality and Health, 3430 BB Nieuwegein, the Netherlands

d Istituto di Ricerche Farmacologiche Mario Negri - IRCCS, Department of Environmental Health Sciences, 20156 Milan, Italy.

\section{*Corresponding authors:}

Lubertus Bijlsma (ORCID: 0000-0001-7005-8775), Environmental and Public Health Analytical

Chemistry, Research Institute for Pesticides and Water, University Jaume I, Avda Sos Baynat s/n, 12071 Castellón, Spain. E-mail address: bijlsma@uji.es

Richard Bade (ORCID: 0000-0003-2724-9183), University of South Australia, UniSA: Clinical and Health Sciences, Health and Biomedical Innovation, South Australia 5000, Australia. E-mail address: Richard.Bade@unisa.edu.au 


\section{Abstract}

23 New psychoactive substances (NPS), often designed as (legal) substitutes to conventional illicit drugs, 24 are constantly emerging in the drug market and being commercialized in different ways and forms. 25 Their use continues to cause public health problems and is therefore of major concern in many 26 countries. Monitoring NPS use, however, is arduous and different sources of information are required 27 to get more insight of the prevalence and diffusion of NPS use. The determination of NPS in pooled 28 urine and wastewater has shown great potential, adding a different and complementary light on this 29 issue. However, it also presents analytical challenges and limitations that must be taken into account 30 such as the complexity of the matrices, the high sensitivity and selectivity required in the analytical 31 methods as a consequence of the low analyte concentrations as well as the rapid transience of NPS 32 on the drug market creating a scenario with constantly moving analytical targets. Analytical 33 investigation of NPS in pooled urine and wastewater is based on liquid chromatography hyphenated 34 to mass spectrometry and can follow different strategies: target, suspect and non-target analysis. This 35 work aims to discuss the advantages and disadvantages of the different data acquisition workflows 36 and data exploration approaches in mass spectrometry, but also pays attention to new developments 37 such as ion mobility and the use of in-silico prediction tools to improve the identification capabilities 38 in high-complex samples. This tutorial gives an insight into this emerging topic of current concern, and 39 describes the experience gathered within different collaborations and projects supported by key 40 research articles and illustrative practical examples.

\section{Keywords}

43 New psychoactive substances; biological samples; wastewater-based epidemiology; monitoring 44 strategies; mass spectrometry; ion mobility separation 


\section{Introduction}

New psychoactive substances (NPS) are continually evolving and introduced in different ways in the drug market. The NPS retail market is characterized by its dynamic nature and the large number of substances covering a broad range of drug categories [1,2]. Whereas most NPS disappear after a short time, others seem to establish a niche market $[2,3]$. They are often introduced as legal substitutes for known controlled drugs, but also explored for their novel effect. Some substances have been known for years and are now misused for recreational purposes, but most NPS are newly synthesized with little or no safety data regarding their short or long-term toxicity. Furthermore, purity and composition of products containing NPS are often not known, which places users at an even higher risk compared to well-known conventional illicit drugs [1,2]. The NPS market is extremely diverse and differs between countries. Governments have responded in different ways to the NPS market, but have not been able to act upon all the NPS which have emerged in an effective way in terms of penalizing its supply and use [4]. Hence, NPS continue to cause public health problems $[5,6]$ and challenge healthcare professionals, toxicologists and policymakers in terms of identification, prevention, treatment and control.

The Early Warning Systems (EWS) established by the European Monitoring Centre for Drugs and Drug Addiction (EMCDDA), Europol and the United Nations Office of Drugs and Crime (UNODC) play a key role in collecting data on new NPS appearing on the market. This information together with indications of the health and social risks associated with these substances is pivotal to respond to the emergence of NPS [7]. Analytical chemistry has a prominent role in gathering more thorough data which allows to better understand the situation of NPS use in the population. To complement the existing sources of information and improve our knowledge about the categories and characteristics of NPS present on the market, the application of appropriate analytical strategies is of utmost importance.

The discovery and characterization of new substances in commercially available products and drug seizures is an important source of information for EWS. Since reference standards for unambiguous confirmation of the identity are often not available, a combination of several techniques, such as nuclear magnetic resonance (NMR), liquid chromatography (LC) coupled to high resolution mass spectrometry (HRMS), gas chromatography mass spectrometry (GC-MS) and X-ray crystallography, is normally applied [8-11]. Although there is a correlation, the identification of new substances in seized products mainly gives information on the NPS available on the market rather than information on the prevalence of use. Therefore, the analysis of biological samples is needed, but this implies a different 
The analysis of biological samples can be considered a frontline in the detection of consumed NPS.

79 Samples of individuals can be collected from, for example, hospital emergency rooms, drug testing 80 campaigns or post-mortem examinations, where concentrations of some NPS in acute intoxications 81 may be relatively high. This may facilitate the identification of hitherto unknown intoxicants by means 82 of the abovementioned analytical techniques [3]. However, it does not give a full picture of NPS use 83 within a community, rather individuals, and the analyses of many samples required to have a wider 84 picture is time consuming and expensive. In contrast, pooled urine and urban wastewater can 85 anonymously provide information of many people in one single aggregated sample. Although the 86 dilution factor can be rather high in these matrices, for example dilution of the sample with urine of 87 non-consumers or water used in households and industry, it has demonstrated its utility for community-wide monitoring of illicit drug use and showed possibilities for getting complementary insight into the consumption and diffusion of NPS use [15-20].

90 Liquid chromatography hyphenated to tandem mass spectrometry instruments (LC-MS/MS) with 91 triple quadrupole mass analyzers (QqQ) or hybrid HRMS/MS systems are the preferred analytical 92 techniques that have the required high sensitivity and selectivity to deal with the challenges related 93 to the screening of NPS in pooled urine and wastewater. Furthermore, the polar characteristics of 94 most NPS and their metabolites, as well as the sample matrix, make them compatible with these 95 techniques. This article aims to discuss the advantages and disadvantages of relevant mass 96 spectrometry (MS) data acquisition workflows and data exploration approaches to confront the low 97 analyte concentrations and ever-changing NPS market and will be supported using key research 98 articles and illustrative practical examples. This tutorial is not intended to be an extensive review of 99 the existing literature, but to give an insight into this timely topic and describes the experience 100 gathered within different collaborations and projects. It also pays attention to new developments such as ion mobility separation (IMS) and the use of in-silico prediction tools to improve the identification capabilities. 


\section{Sample collection and sample treatment}

104

105

106

107

108

109

110

111

112

Well-designed protocols for sample collection and storage, and versatile sample treatment of pooled urine and wastewater are essential for getting data that provide meaningful information on NPS use. The collection of anonymous pooled urine samples from portable street urinals has recently demonstrated its utility to detect the use of recreational drugs, including NPS $[18,19]$. Generally, multiple samples are taken from various urine reservoirs, over a 12-hour period, and then mixed to form pooled urine samples. This sampling method can be applied in cities where stand-alone urinals are routinely used at weekends [19], but can also be used for monitoring specific night time settings or recreational events such as music festivals [20-24]. Sampling urine aliquots from urinals ensures the collection of anonymous and representative samples and results may reflect the direct use of NPS. Yet, some limitations are related to the fact that urinals are designed for male use only and normally have no 'flushing' mechanism [25]. Thus, the number of contributors to the samples is unknown and, although quantitative analysis is possible, the comparison of concentrations gives little additional insight rather than a qualitative overview of the actual use of a certain drug compared to the other substances quantified in that specific sample.

Wastewater analysis may circumvent these limitations by providing anonymous populationnormalized information of an entire community and has recently been explored to gather information on NPS use $[3,15,17,26,27]$. The successful application of wastewater-based epidemiology for assessing spatial differences and temporal changes in illicit drug use has been demonstrated $[28,29]$ where population-normalized data can be calculated taking into account the measured concentration, the daily flow rate of sewage and the number of people connected to the wastewater treatment plant (WWTP) $[28,30]$. Specific sampling protocols have been developed to obtain representative 24-hour composite wastewater samples collected at the inlet of a WWTP [28]. In addition, a standardized questionnaire facilitates the collection of relevant meta-data such as the daily flow rate of sewage and the number of people connected to the WWTP [31]. This meta-data allows quantitative populationnormalized information for a limited number of target NPS to be explored. The information provided by wastewater analysis can be integrated with existing epidemiological data because of the unique ability to provide objective, updated and nearly real-time information on drug use [16,32].

One sampling technique not yet fully explored but with potential for monitoring NPS in wastewater is passive sampling [33], which ensures the concentration of analytes from longer periods (days or weeks) and increases the possibility to detect substances with low prevalence of use. The main advantage is that passive samplers, consisting of polymeric-based sorbent material, deployed for longer periods, can accumulate trace analytes on the sorbent during this period. Moreover, as some NPS might be consumed sporadically (and thus might not always be present in wastewater), one does 
137 not need to collect multiple wastewater samples, which all eventually need to be processed i.e. 138 increasing labor costs. Hence, this technology offers practical and economic advantages for gathering 139 long-term data. But it has also some challenges related to calibration and quantification, since they 140 require knowledge about uptake and diffusion of the different substances and are subject to the 141 variability associated with NPS stability and environmental factors (e.g., flow rates, biofouling) [33,34].

142 The uptake of target analytes on sorbent materials needs, therefore, to be determined prior to 143 deployment in the sampling site.

144 Stability of NPS is an important aspect of sample collection for both pooled urine and wastewater 145 analysis. While specific stability studies in pooled urine samples are lacking, they have been carried 146 out on urine samples for forensic toxicology purposes. Metabolites of synthetic cannabinoids have 147 been shown to be stable up to 14 days when refrigerated [35]. Many synthetic cathinones, 148 benzodiazepines and amphetamine-type derivatives are very stable under freezing $\left(-20^{\circ} \mathrm{C}\right)$ storage 149 conditions for months-years. However, when stored at room temperature or even refrigerated, 150 degradation of these compounds can occur within days [36-38]. Therefore, it is recommended to 151 freeze pooled urine samples immediately upon collection to avoid degradation. Regarding 152 wastewater, it has been shown that acidification to $\mathrm{pH} 2$ improves the stability in both filtered and 153 unfiltered wastewater for up to 14 days for a wide variety of NPS such as cathinones, 154 phenethylamines, opioid-derivatives and amphetamine-like stimulants [39]. If samples cannot be 155 acidified, it is recommended that they are kept either refrigerated $\left(4^{\circ} \mathrm{C}\right)$ or frozen $\left(-20^{\circ} \mathrm{C}\right)$ for no longer 156 than one week prior to sample processing [39-42]. Several synthetic cannabinoids have been shown 157 to be unstable at $\mathrm{pH} 2$ and in raw wastewater i.e. the hydroxypentyl metabolites of JWH 122, AM 158 2201, RCS-4 and JWH 073, while JWH 018 n-pentanoic acid, JWH 073 N-butanoic acid and JWH018 N159 5-hydroxypentyl were stable at room temperature for up to 24 hours [42]. Moreover, the use of 160 sodium metabisulfite as a preservative has been recommended to improve the stability of synthetic 161 cannabinoids [43].

162 A non-selective and versatile sample preparation protocol for the enrichment and clean-up of samples 163 capable of retaining a wide range of NPS with broad physicochemical properties is preferred and 164 applied by the vast majority of reported studies. Pooled urine samples are usually treated by 165 performing a hydrolysis step to cleave drug-glucuronide conjugates with $\beta$-glucuronidase and 166 arylsulfatase prior to solid-phase extraction (SPE), liquid-liquid extraction and/or dilute and shoot 167 techniques $[21,44,45]$, while wastewater samples do generally not require this hydrolysis step due to 168 in-sewer deconjugation [46-50] and are normally filtered and solid-phase extracted [17], although a 169 less labor-intensive and quicker preparation procedure following the QuECHeRS principle has also 170 been applied [51]. In order to cover the broadest range of substances possible, multiple SPE cartridges 
171 or cartridges consisting of several layers with different stationary phase chemistries can be used $172[27,52]$. The use of more cartridges implies several separate extractions, yet these can be optimized 173 to specific NPS categories of interest such as cathinones or synthetic cannabinoids [15,21]. Typically, 174 cartridges containing polymeric-based SPE sorbents with reversed phase (RP) properties built of 175 generic hydrophilic and lipophilic balanced monomers or strong cation-exchange mixed mode 176 sorbents incorporating RP copolymers are used. For the latter, samples should be acidified to pH 2-3 177 to ensure that the analytes are positively charged during extraction [53]. This especially aids the 178 recovery of cathinones, amphetamine-like stimulants, opioid derivatives and phenethylamines $179[21,39,45,54,55]$. Online SPE has also been utilized for a limited number of NPS using a RP cartridge, 180 with satisfactory recovery (i.e. 70-120\%) [56]. LLE has been shown to aid in the detection of synthetic 181 cannabinoids in pooled urine [57] and wastewater [43,58]. For wastewater studies, it is important to 182 note that the removal of the solid fraction through filtration can greatly affect the overall recovery of 183 synthetic cannabinoids due to their lipophilicity. Therefore, when performing wastewater analysis, 184 both the aqueous and particulate fraction should be extracted together for optimal recovery of 185 cannabinoids.

186 Although both pooled urine and wastewater analyses incorporate SPE, there is a much lower pre187 concentration factor needed for pooled urine, with initial volumes of $1-2 \mathrm{~mL}$, due to the generally 188 higher concentrations found $[23,45,57]$. Furthermore, lower pre-concentration results in less matrix 189 effects and potentially an improved chromatographic performance. Higher pre-concentration factors 190 in wastewater are commonly applied to deal with the very low concentrations of NPS expected in 191 these samples. However, this can also result in strong matrix effects due to the pre-concentration of 192 unremoved components present in the sample extract. Matrix effects are alterations of the MS signal 193 (enhancement or suppression), which have been linked to co-eluting interferences such as proteins, 194 lipids, sugars or salts, that affect the ionization process [59]. Frequently, isotopically labelled internal 195 standards (ILIS) are used as surrogates and added to samples prior to processing (i.e., SPE) or analysis 196 (in the case of dilute and shoot approaches applied in pooled urine analysis), to account for potential 197 matrix effects, but also to correct for potential errors due to sample preparation. Ideally ILIS of the 198 corresponding NPS are used as they are supposed to be affected in a similar manner as their non199 labelled counterparts. However, ILIS are often expensive and not always commercially available, 200 especially in the case of NPS. Therefore, ILIS are regularly used to correct for several compounds $201[15,40]$. Nevertheless, the performance of each ILIS for correcting matrix effects need to be carefully 202 evaluated. When appropriate ILIS are unavailable, matrix effects may be minimized by applying an 203 additional clean-up step, but also lower pre-concentration factors may occasionally be desired for 204 some substances in order to reduce ionization suppression and increase their detection limit $[27,60]$. 
205 In general, even when ILIS are available, a reduction of matrix effects is recommended for better 206 precision, sensitivity and robustness in complex matrix samples [60]. 


\section{Chromatographic separation}

208 Good chromatographic separation is important to reach the required levels of selectivity, sensitivity and identification power to monitor NPS through wastewater and pooled urine analysis. GC-MS has been applied for the determination of NPS in urine. However, because of the high levels of selectivity and sensitivity provided by this technique, it requires the derivatization of the analytes which results in a more time-consuming and less generic sample treatment [61,62]. Alternatively, LC-MS allows the determination of compounds with a broad range of polarity, low volatility and thermolability with the application of more generic sample treatment strategies. In addition, the aqueous nature of the matrices makes LC-MS fully compatible with the determination of NPS in wastewater and pooled urine samples [63].

Reverse-phase LC (RPLC) separates compounds within the range of low-polarity to non-polarity. Therefore, it seems to be the most suitable chromatographic technique to achieve generic and good chromatographic separation especially for wide-scope monitoring of NPS. Consequently, the vast majority of studies dealing with multi-residue methods in wastewater and/or pooled urine samples applied RPLC as the separation technique $[13,23,25,64,65]$. However, more polar (or ionic) substances such as amphetamine-like stimulants or synthetic cathinones and their metabolites, might require more specific methodologies. Recent developments in column chemistries and improvement in robustness of existing stationary phases allowed the analysis of more particular scenarios. Hydrophilic interaction LC (HILIC) is an alternative approach to effectively separate small and highly polar NPS. For example, Kinyua et al. [55] successfully developed a multi-residue methodology for the determination of 7 synthetic cathinones and amphetamine-like stimulants by means of HILIC separation. Additionally, enantiomeric analysis has also been explored for the determination of NPS [66-68]. Chiral NPS are usually consumed as racemic mixtures of different forms (i.e. with an enantiomeric fraction (EF) between the two forms of approximately 0.5 ), even though both forms might differ quantitatively and qualitatively in the pharmacological activity [69]. Therefore, enrichment of the R (or S) form, depending on the stereoselective metabolism in humans, is expected in biological samples [66]. Consequently, an EF found in wastewater or pooled urine samples deviated from the original EF value could help in distinguishing between human consumption and direct disposal of unused substances [66]. Other chromatographic techniques such as capillary chromatography and supercritical fluid chromatography (SFC) are promising strategies for the monitoring of NPS. The improvement in sensitivity provided by capillary chromatography, especially for the small amphetamine-like structures, revealed a technique to explore for this purpose [26]. Also, recent developments in commercially available instruments has seen an increase in applications of ultra-high 
241 various organic additives as mobile phase $[58,70]$. One of the main advantages of UHPSFC compared 242 to conventional UHPLC is its increased chromatographic efficiency and resolution [71] also permitting 243 the separation of several NPS isomers with good results [72]. 
As discussed above, the determination of NPS can be challenging due to the large number of potentially relevant compounds and the low concentrations expected in samples, in particular when considering wastewater and pooled urine. In fact, due to the often low prevalence of use of individual compounds, concentrations of these substances are often orders of magnitudes lower compared to conventional illicit drugs $\left(<10 \mathrm{ng} \mathrm{L}^{-1}\right)$ [55]. For this reason, targeted methods, specifically using LCMS/MS with QqQ or ion-trap mass analyzers, have been implemented for the reliable identification and quantification of selected NPS in urine and wastewater samples $[15,17,73,74]$. The development of such quantitative target methods, however, requires access to reference standards for precursorproduct ion transition selection in the Selected Reaction Monitoring (SRM) mode and MS parameters optimization. Identification and confirmation is achieved through the acquisition of at least two SRM transitions and matching of the retention time (RT) and ion-intensity ratios between the sample and reference standard [75,76]. The most sensitive SRM transition is commonly selected for the Synthetic cathinones, phenethylamines, tryptamines and piperazine-derivatives have been quantitatively determined in pooled urine samples collected during weekends at specific night settings [25] or at music festivals [23]. Although data obtained from quantitative determination of NPS in pooled urine samples only gives an indication on the extent of use for an NPS compared to other quantification at low concentration levels, whereas the second transition allows confident confirmation $[26,40,46]$. However, since NPS often retain high structural similarity, the risk of selecting common transitions is present and therefore the acquisition of more transitions (if feasible) is recommended to gain more confidence to the confirmation process. Hence, it is also important to understand fragmentation of each NPS as it allows the selection of specific product ions and avoid non-specific transitions such as a neutral loss of water or $\mathrm{CO}_{2}[77]$. The latter is especially relevant to minimize potential matrix interferences when analyzing NPS at low concentrations in highly complex matrices such as pooled urine and raw wastewater samples. Although quantitative target monitoring can be performed using LC-HRMS instruments, their application in the field is limited due to the generally lower sensitivity compared to low resolution MS/MS instruments [17]. Hence, the advantage of low-resolution instruments for quantitative analysis lies in the robustness, selectivity and sensitivity which can be achieved by monitoring these specific precursor-product ion transitions. Combined with their high scanning speed, these instruments can monitor many transitions almost simultaneously, and consequently high-throughput, multi-residue methods that include many targeted NPS biomarkers, can relatively easily be developed. substances found in a specific sample [23], these findings are still very valuable, as the application of these selective and sensitive target quantitative methods give high confidence and allows 
278 confirmation of the NPS identified at low concentration levels. Synthetic cathinones are by far the 279 most studied group of NPS in wastewater, followed by synthetic cannabinoids and phenethylamines. 280 Studies using LC-MS/MS to monitor these substances have been carried out in Europe, Asia and 281 Australia $[15,17,26,39,40,78,79]$ and have shown spatial and temporal trends using population282 normalized data. Although LC-MS/MS methods are highly sensitive and multi-residue methods can be 283 developed, they have a major drawback, namely reference standard materials need to be available 284 for method development as previously highlighted. Given the high number of NPS that have been 285 detected in the market and their transient nature, reference standards are mostly available for only a 286 limited number of compounds. Moreover, by the time reference standards become available, these 287 compounds might have already disappeared from the market as they may have been less popular or 288 added to the lists of regulated substances and can thus not be sold legally anymore. Further 289 exacerbating the determination of these substances is the extent of their metabolism. There have 290 been studies carried out on the metabolism of NPS using human liver microsome incubations to better 291 understand the metabolism of certain NPS [80-84]. In addition, recent advances in computing power 292 have permitted the development of comprehensive knowledge based software to predict the 293 metabolic fate $[85,86]$. However, reference standards of most of the metabolites proposed are not 294 commercially available and therefore unsuitable for quantitative target monitoring. Thus, quantitative 295 target LC-MS/MS methods, although indispensable to achieve the highest sensitivity needed for 296 certain types of substances (e.g., fentanyl and its derivatives), need to be complemented by other 297 analytical approaches which allow a quick and broader monitoring, without the necessity for reference 298 standards. Although low-resolution mass spectrometry (LRMS), especially tandem MS instruments, 299 are highly appreciated in quantitative analysis, its application to qualitative analysis and capabilities in 300 detecting unknowns is, limited due to the relative low resolving power (approximately $1 \mathrm{Da}$ ) and low 301 sensitivity in full scan mode [77]. The use of HRMS offers new possibilities in the determination of NPS 302 as well as circumventing some of the limitations of LRMS. 


\section{Qualitative screening approaches}

304

305

306

307

308

309

310

311

312

313

314

315

316

317

318

319

320

321

322

323

324

325

326

327

328

329

330

331

332

333

334

335

336

HRMS presents strong potential for monitoring a large number of substances, due to its acquisition of accurate-mass full spectrum data at good sensitivity $[63,77,87]$. In order to facilitate the reading of this tutorial, terms that will be used in this section are defined below:

Target screening based on HRMS allows the qualitative screening of NPS after data acquisition based on large databases, thus evading the pre-selection of analytes for method development and the need of reference standards. However, the information included in the database is limited by the availability of reference standards. When reference standards are available, information such as accurate masses of fragment ions, adduct formation and RT can be included, whereas only the elemental composition, exact mass and theoretical isotopic pattern can be included when no reference standard is available. Although the acquisition of data is performed in an untargeted way, the approach is considered targeted and generally known as suspect screening $[77,87]$, since the search is based on a list of target compounds that can be expected to be found in the samples. An advantage of this approach is that retrospective analysis can also be performed at any time from the acquired data to search for substances initially not considered and included in the database, such as novel NPS or newly discovered metabolites $[88,89]$. It should, however, be noted that the detection of some substances might be restricted by the sample treatment, the chromatographic conditions or the ionization efficiency [90], since usually a generic analysis is performed and no optimization has been executed for the NPS included in the database.

Non-targeted screening, without any selection of analytes, allows the investigation of any other NPS biomarker not included in the database. However, it implies an examination of each chromatographic peak and extensive investigation of its accurate mass spectrum. This process is challenging and time consuming and probably does not outweigh the rate of success in identifying of unknown NPS. Alternatively, the screening can be directed to discover related compounds of known NPS using characteristic mass spectral information and applying mass-defect filtering or common fragmentation pathways.

As a starting point for researchers interested in undertaking qualitative screening of NPS by HRMS, the review article written by Hernandez et al. [63] describing different mass spectrometric strategies for the investigation of illicit drug biomarkers in wastewater is recommended. Although similar strategies and identification criteria can be applied for the investigation of NPS in pooled urine and wastewater, the challenges are different due to the rapid turnover in the NPS drug market creating a scenario with constantly moving analytical targets and the often lower prevalence of use compared to conventional illicit drugs. Moreover, the structural similarities of NPS and their metabolites often requires increased identification confidence in order to minimize reporting false positives. In the text 
below, practical examples are given to discuss different data acquisition workflows and data exploration approaches to illustrate how HRMS can help in the confident identification of NPS in highcomplex pooled urine and wastewater samples.

\subsection{Acquisition modes for hybrid high resolution mass spectrometric systems}

The most commonly used HRMS analyzers are time-of-flight (TOF) and Orbitrap, which can be coupled with LC and possess high mass resolving power (> 20,000 Full Width at Half Maximum (FWHM)) and mass accuracy $(<5 \mathrm{ppm})$ for wide scope screening of NPS in pooled urine and wastewater $[17,75,76]$. However, hybrid configurations, such as quadrupole-TOF (QTOF) or quadrupole-Orbitrap (Q-Orbitrap), are nowadays more the standard than the exception as they considerably increase the potential of HRMS for screening NPS $[20,21,27,44,52,91]$. When working in MS/MS mode, it is possible to record accurate mass product-ion spectra of previously detected candidates and obtain relevant structural information to allow suspected NPS to be confidently identified or disregarded as false positives. However, the simultaneous accurate-mass acquisition of both full-spectrum and product-ion spectra data is preferable and collects accurate mass data of both the (de)protonated molecules and its fragment ions in a single acquisition and without the selection of precursor ions.

In data-dependent acquisition (DDA) mode, the instrument first performs a "survey scan" from which the analyst chooses (or not) certain ions that fit specific criteria based on, for example, intensity thresholds. Ions for which these conditions are met, are then selected to be included in a list of preselected masses and fragmented to provide information-rich product ion scans. Unlike intensity thresholds, an inclusion (or exclusion) list allows large matrix interferences to be ignored, thereby facilitating the identification process and saving effort and time $[27,52,63,92]$. However, the size of the inclusion list (i.e., suspects to be fragmented) can adversely affect the cycle time of the instrument. Therefore, a decrease in the number of scans (or data points) across a chromatographic peak will occur, reducing its detectability. Moreover, any compound not included in the initial inclusion list cannot later be retrospectively analyzed, so the sample would have to be re-extracted and reanalyzed. Yet, there is a way around this limitation, utilizing complementary targeted and untargeted DDA. This technique initially conducts an MS scan followed by targeted MS/MS using an inclusion list and then untargeted MS/MS on $n$-selected precursors. For example, analysts can look at MS/MS of the $n$ most abundant precursor ions, which would be of great utility for samples with high levels of NPS such as seizure samples [14,93]. However, the generally low concentration of NPS found in pooled urine and wastewater might mask the detection of low abundant peaks, and therefore, many NPS may remain undetected [94]. 
Data independent acquisition (DIA) allows the acquisition of accurate-mass full-scan spectra under different collision induced dissociation conditions within a single injection. This acquisition mode is known under different names depending on the manufacturer (e.g. All-ion-fragmentation (AIF), allion $\mathrm{MS} / \mathrm{MS}, \mathrm{MS}^{\mathrm{E}}$ and broadband collision-induced dissociation (bbCID)), where all ions generated in the ion source are sent to the collision cell for fragmentation without precursor ion selection or any predefined selection criteria. This alternation between full-scan and untargeted MS/MS events at low collision energy (LE) and high collision energy (HE), respectively, allows one to obtain information relating to the accurate masses of the (de)protonated molecule as well as their fragment ions. Furthermore, it conserves highly valuable information on adducts and isotopes since the quadrupole works as an ion guide $[63,77]$. The main limitation of DIA is that spectra are non-selective and contain product ions for all ions formed in the ion source. Hence, the interpretation can be challenging, since co-eluting compounds or matrix interferences may "contaminate" the spectra, and makes it difficult to associate product ions with the correct (de)protonated molecule $[14,95,96]$.

Slightly different modes compared to the other DIA modes mentioned above in terms of specificity have been developed by manufacturers with the objective to have HE spectra approaching to MS/MS quality data. As an example, in Sequential Window Acquisition of all THeoretical fragment ion spectra (SWATH) mode, a TOF MS full scan at LE is acquired, alternated by SWATH experiments at HE obtaining MS/MS data by fragmenting only the (de)protonated molecules present in a much narrower window (e.g. $15-25 \mathrm{~m} / \mathrm{z}$ ). In this way, SWATH can distinguish co-eluting compounds of different masses by having specific experimental mass fragmentation windows which filter out all masses not included in the specified mass range. This results in cleaner spectra, which facilitates identification $[96,97]$. This is a particular important point in the determination of NPS, which are notorious for the analytical challenges associated with common fragments. Figure 1 shows the utility of SWATH in differentiating two co-eluting NPS, butyryl fentanyl with $\mathrm{m} / \mathrm{z} 351.2431$ and furanylfentanyl with $\mathrm{m} / \mathrm{z} 375.2067$ in a spiked wastewater sample. In the full scan acquisition at LE, it can be observed from the individual extraction ion chromatograms (XICs) that the two NPS seemingly elute at $12.50 \mathrm{~min}$ (Figure 1A, top), with the mass spectra at this RT showing both masses (Figure 1A, bottom). However, when applying SWATH, the HE experiments carried out at different mass windows $(\mathrm{m} / \mathrm{z} 340.2-357.4$; Figure 1B and $\mathrm{m} / \mathrm{z} 372.6$-389.8; Figure $1 \mathrm{C}$ ) allowed them to be distinguished by extracting the mass of each of these fentanyl derivatives in their corresponding acquisition window. With the mass of butyryl fentanyl and furanylfentanyl falling within separate experiments, they can be individually extracted and identified using cleaner spectra. This exemplifies the power of this acquisition mode in the elucidation of NPS. 
[Insert Figure 1 here: Identification of two co-eluting NPS, butyryl fentanyl ( $m / z$ 351.2431) and furanylfentanyl (m/z 375.2067) in a spiked wastewater sample using Sequential Window Acquisition of all THeoretical fragment ion spectra (SWATH). (A) overlapping extraction ion chromatograms (XICs) of the two NPS with chromatographic peaks eluting at $12.50 \mathrm{~min}$ (top); full scan acquisition mass spectra with low collision energy (LE) (10 V) at retention time $12.50 \pm$ $0.10 \mathrm{~min}$ (bottom). (B) SWATH mass window $\mathrm{m} / \mathrm{z}$ 340.2-357.4, XIC at $\mathrm{m} / \mathrm{z} 351.24$ (middle) and high collision energy (HE) mass spectra (bottom); (C) SWATH mass window m/z 372.6-389.8, XIC at $m / z 375.21$ (middle) and HE mass spectra (bottom)]

\subsection{Suspect screening}

Suspect screening approaches usually take advantage of home-made databases. However, the information included therein is limited by the availability of reference standards, as previously explained. When no reference standard is available, the minimum suggested requirements for a tentative identification is the accurate mass of the (de)protonated molecule and, at least, one significant fragment ion together with the corresponding isotopic pattern. This is in the line with proposed quality procedures recommended in other research fields $[76,98]$. The observed fragments need to be in accordance with the chemical structure and, preferably, in agreement with previously reported data in scientific literature or online spectral databases $[27,52,99,100]$. Ideally, reference standards are available, and information such as accurate masses of fragment ions, adduct formation and RT can be included, which allow unequivocal identification. However, this entails high costs due to the high number of compounds and, therefore, huge efforts have been devoted, in the recent years, to develop community-made or online mass spectral databases for NPS. The best known databases are NPS Data Hub [101] and HighResNPS [102,103] with more than 2800 and 3350 entries, respectively (date accessed: 26 June 2020). The HighResNPS library currently has active users from more than 10 laboratories around the world with the intention to ensure up-to-date analytical information from the moment a specific NPS becomes available to a given participating laboratory [102]. These libraries are available to help and facilitate the screening of NPS and their metabolites [101,104-106].

In most laboratories, a suspect screening based on large home-made databases is often the first step for monitoring samples. Due to the high number of NPS and metabolites, the rapid transience of these compounds on the market, high costs and limited availability of reference standards, home-made databases are normally built of merely accurate masses of the (de)protonated NPS and fragment ions. Yet, the low concentration levels of NPS present in combination with strong matrix interferences makes the tentative identification of NPS challenging and remark often the necessity to perform some additional research or experiments to increase the confidence in the tentative identification. As an 
437 example, Figure 2 shows the tentative identification of 4-chloro- $\alpha$-pyrrolidinopropiophenone (4438 chloro- $\alpha$-PPP) in a pooled urine sample. Its protonated molecule, the isotopic information related to 439 the presence of one chlorine atom and at least one fragment ion was observed at accurate mass 440 (Figure 2A). However, a known and abundant fragment of 4-chloro- $\alpha$-PPP at $m / z 167.0258$ [107] 441 showed an undue high mass error (+143 ppm) under the initial screening conditions, which made the 442 tentative identification of this NPS questionable. By increasing the mass resolution of the Orbitrap MS 443 from 20.000 to $35.000 \mathrm{FWHM}$ and zooming in the $\mathrm{m} / \mathrm{z}$ range of the fragment, it was possible to 444 distinguish three peaks at $m / z 167$, one corresponding to the fragment ion $\mathrm{m} / \mathrm{z} 167.0258$ (+5.3 ppm) 445 of 4-chloro- $\alpha$-PPP (Figure 2B, bottom). This allowed more confidence to be gained in the 446 identification. Subsequently, the feature could be identified as 4-chloro- $\alpha$-PPP by means of a reference 447 standard. The latter is pivotal for the confirmation of the identity of the NPS. However, by using this 448 approach, laboratories do not need to purchase all reference standards a priori to the analysis [108] 449 and could prioritize those NPS for which more reliable evidence is obtained.

[Insert Figure 2 here: Tentative identification of 4 '-chloro- $\alpha$-pyrrolidinopropiophenone (4-chloro- $\alpha$ PPP) in a pooled urine sample. (A) Extracted ion chromatogram of 4-chloro- $\alpha$-PPP and ${ }^{37} \mathrm{Cl}$ isotope (top); Product ion mass spectra of $[\mathrm{M}+\mathrm{H}]^{+}$at $\mathrm{m} / \mathrm{z} 238.10$ (bottom). (B) Structure of 4chloro- $\alpha$-PPP (top); Zoom in the range of fragment ion with $\mathrm{m} / \mathrm{z} 167$ at resolution (R) of 35.000 Full Width at Half Maximum (FWHM) (bottom)]

Positional isomers or homologues are frequently the first choice to substitute banned NPS [109]. Hence, NPS often have only minor modifications to a backbone structure and the structural similarities of NPS and their metabolites are often reflected by their common fragmentation pathways, this poses one of the principal challenges in suspect screening strategies. As an example, the analysis of a raw wastewater sample showed a chromatographic peak at 4.51 min giving a positive hit for the isomers $\alpha$-methyltryptamine (AMT) and 5-(2-aminopropyl)indole (5-IT) based on the accurate mass of their protonated molecule and their fragment ions (Figure 3A). These two isomers share the same chemical backbone with the only difference being the position of the substituent (Figure 3B and 3C, top). The following MS fragment ions were found: $m / z$ 158.0954, $m / z$ 143.0724, $m / z$ 132.0799, m/z 117.0577 and $m / z$ 115.0541, with the most abundant fragment at $m / z 143.0724$ (Figure 3A, bottom). The only difference, described in the literature, between the spectra of AMT and 5-IT resides in the relative intensities of the fragment ions [110]. The most intense fragment ion of 5-IT has an $m / z$ of 130 , whereas the most abundant fragment ion for AMT corresponds to $m / z 143$. This slight difference in the fragmentation pattern (i.e. intensities) gave more confidence in the tentative identification of AMT 
471 instead of 5-IT in this sample. Therefore, AMT was synthesized and a reference standard of 5-IT was 472 donated by a collaborating laboratory. When comparing that empirical data to AMT and 5-IT reference 473 standard MS fragment ions (Figure $\mathbf{3 b}$ and $\mathbf{3 c}$, bottom), it can be observed that both substances share 474 the same fragment ions (in nominal mass; $m / z 143, m / z$ 130, $m / z 117$ and $m / z$ 115) coinciding with 475 the fragment ions observed in the sample, but that AMT indeed show a more abundant fragment ion 476 with $m / z$ 143. This gave more confidence in the positive identification of this NPS and together with 477 its RT, AMT could finally be confirmed.

[Insert Figure 3 here: Identification of $\alpha$-methyltryptamine in a raw wastewater sample using QTOF MS. (A) feature detection of $\mathrm{m} / \mathrm{z} 175.1235$ at $4.51 \mathrm{~min}$ (top, insert) together with the low collision energy (LE) spectra (top) and high collision energy (HE) spectra with emphasis on $\mathrm{m} / \mathrm{z}$ 130-145 (grey areas) (bottom); (B) Structure, fragment ions, LE and HE spectra of $\alpha$ methyltryptamine; (C) Structure, fragment ions, LE and HE spectra of 5-(2-aminopropyl)indole]

\subsection{In-silico approaches}

In some cases, the instrument-specific parameters (i.e. accurate mass ions and isotopic patterns) do not suffice to tentatively propose a chemical structure, and, therefore, additional studies are required. For that purpose, predictive models have been used to filter out false positives and increase the confidence of compound identification when reference standards are unavailable or no information is within reach in previously reported data $[27,111,112]$. Aalizadeh et al. developed a RT prediction model using Quantitative Structure-Retention Relationships (QSSR) and Support Vector Machines (SVM) to model the RT data for both HILIC and RPLC with high accuracy [111]. A different approach was proposed by Bade et al. considering the application of Artificial Neural Networks (ANNs) for the development of a RT predictor for gradient-RPLC using a dataset of more than 500 compounds with an predictor accuracy of $\pm 2 \mathrm{~min}$ [112]. Such RT predictive tools are highly valuable for the determination of NPS in complex matrices as demonstrated by Diamanti et al. [27]. Since the availability of reference standards is limited, the suspect screening of NPS usually results in many candidate structures because of the structural similarity of many NPS, as for example, in the case of the two isomeric phenethylamines 3,4-methylenedioxy-N-hydroxyethylamphetamine (MDHOET) and $\mathrm{N}$-hydroxy- $\mathrm{N}$-methyl-3,4-ethylenedioxyamphetamine (EFLEA). The predicted RT using a QSSR predictor model matched the one for MDHOET and discarded the one for EFLEA, thereby reducing the number of candidates and increasing the confidence in the tentative identification of MDHOET in influent wastewater from Athens [27]. In-silico fragmentation tools, such as the MetFrag software, are pivotal in a suspect screening workflow. This software generates a predicted fragmentation of 
505 molecules based on their structure and compare it to the empirical data gathered proposing a list of

506 fitting candidates together with a scoring parameter [113,114]. However, it is common that many

507 structurally related substances can be assigned to the empirical data with a similar score value [113],

508 which is a drawback particularly for the investigation of NPS because of the similarity of several

509 substances. 


\section{Ion mobility separation coupled to high resolution mass spectrometry}

511 The recent development of the hyphenation of IMS with LC-QTOF MS instruments (LC-IMS-QTOF MS) 512 represents an innovative tool for their application in target and non-targeted screening strategies. IMS 513 separates ions depending on their size, shape and charge in a gas phase, (usually nitrogen or helium), 514 and in the presence of an electric field [115]. Ion separation occurs in the millisecond time scale, 515 making it compatible with fast TOF MS acquisitions [116]. The time an ion takes to travel through the 516 mobility cell i.e. the drift time (DT), adds an extra dimension to the obtained chromatographic RT and 517 accurate mass, which results in increased selectivity and improved identification, particularly in DIA 518 modes $[116,117]$. The increased selectivity is translated into much cleaner and higher-quality spectra 519 than conventional HRMS DIA spectra, since (de)protonated molecules and fragment ions of interest 520 with the same DT can be aligned and separated from co-eluting matrix components. Although data 521 sets inherently become more complex and more comprehensive, the utilization of IMS-HRMS 522 instruments does not overcomplicate the data revision process thanks to the four-dimensional 523 automatic feature detection. This allows the software to both deconvolute peaks based on 524 chromatographic and MS data and align ions with the same RT and DT into unique features. Thus, LE 525 and HE spectra are DT filtered for the deconvoluted ions (i.e. for each ion detected in the LE spectra 526 its DT is used to correlate it with the fragment ions obtained in the HE spectra). Cleaner spectra can 527 also be obtained by improving the chromatographic separation. Although improvements in the quality 528 of the spectra often relies on spectral discrimination of the compounds, a good chromatographic separation is recommended especially when analyzing complex matrices such as pooled urine and wastewater that contain many co-eluting interferences. Yet, IMS provides an extra dimension of separation which fits between chromatography and MS and results in cleaner spectra, but without increasing the chromatographic run time or mass resolving power.

A further advantage of IMS is that Collision Cross Section (CCS) values can be derived from the DT and represent the surface of the sphere created by the ion when moving in the gas phase. Unlike DT, CCS is an instrument independent value, provided that the same drift gas and ion mobility calibration standards are used $[116,118,119]$. The importance of CCS values relies on the fact that they are robust across multiple platforms (i.e. deviation up to $2 \%$ ), independent of the chromatographic conditions used and not affected by matrix composition [118-120]. CCS values depend on the calibration procedure applied, and the deviation between instruments is caused by the slight experimental variations in room temperature, gas pressures and other hardware settings. Hence, CCS is a parameter that can give support to MS-based compound identification in addition to RT, $m / z$, isotopic pattern and fragment ions. Finally, IMS enables, in theory, the separation of isomeric compounds not previously resolved using LC, since they are expected to have a different mobility in the drift cell, and 
544 therefore different CCS values [121,122]. Although there is a relationship between the $m / z$ and CCS,

545 Bijlsma et al. [123] showed that a range of $35 \AA^{2}$ could be observed for molecules of approximately

$546300 \mathrm{Da}$, therefore, demonstrating that no direct correlation between $\mathrm{m} / \mathrm{z}$ and CCS could be established

547 and that thus IMS may separate isomers.

548 Figure 4 illustrates the benefits of IMS in terms of higher-quality spectra in DIA MS/MS events. In this

549 example, a positive finding of ketamine in a wastewater sample is shown using an ion mobility 550 separation QTOF MS (Vion from Waters). When searching for ketamine (with $\mathrm{m} / \mathrm{z} 238.0993 \leq 5 \mathrm{ppm}$ )

551 a chromatographic peak at a RT of 3.33 min was observed (Figure 4A, top (yellow arrow)). The 552 corresponding conventional DIA MSE spectra (LE and HE) show many ions when no DT alignment is 553 applied (Figure 4B, top) resulting in a base peak with $\mathrm{m} / \mathrm{z} 263.1386$, which does not correspond to 554 ketamine (i.e. $\mathrm{m} / \mathrm{z}$ 238.0993, highlighted in green). However, when applying the IMS MS ${ }^{\mathrm{E}}$ acquisition 555 mode $\left(\mathrm{HDMS}^{\mathrm{E}}\right.$, High-Definition MS ${ }^{\mathrm{E}}$ ), several co-eluting ions at $3.33 \mathrm{~min}$ are separated in the mobility 556 cell, illustrated as red or black dots in Figure 4A, bottom. The DT of the ion with $\mathrm{m} / \mathrm{z} 238.0993$ was $5574.89 \pm 0.20 \mathrm{~ms}$ and the corresponding fragment ions in this range, the blue highlighted areas, can be 558 aligned. All other ions outside this area are filtered out, which results in much cleaner and easier to 559 interpret spectra (Figure 4B, bottom). Despite the presence of some co-eluting interferences with 560 similar DT, the resulting spectra contains fragment ions which could be primarily assigned to ketamine 561 [124].

The additional cleaning of spectra provided by IMS is of particular relevance for the determination of NPS in challenging matrices such as wastewater or pooled urine where thousands of naturally occurring compounds can hamper the identification of these substances at the low concentration levels expected. Moreover, since the CCS value of a certain molecule is not affected by matrix composition, their utilization as an additional identification point in the determination of NPS pushes

575 IMS-HRMS as a promising technique in the monitoring of these substances $[125,126]$. Therefore, the 576 development of home-made or collaborative on-line databases including ion mobility data will 577 enhance the efficiency of target NPS screening. However, as has been discussed earlier, due to the 
578 lack of analytical standards for most of the NPS and metabolites and the still sparse accessibility to 579 IMS-HRMS instruments in research centers, the availability of CCS values for these substances is still 580 very limited. Hence, in-silico predictive tools similar to those for RT and MS fragmentation may help 581 to increase the confidence in the identification of tentative candidates. Several data-driven CCS 582 predictor systems have been developed for the prediction of CCS values for small molecules [123], 583 pharmaceuticals and drugs of abuse [127] and metabolites [128]. As an example, the predictor 584 reported by Bijlsma and Bade et al. [123] was developed using 205 CCS values for small molecules 585 including pharmaceuticals, pesticides and drugs of abuse with ANNs for modelling the ion mobility 586 data. Although the empirical variability of CCS measurements across instruments for a certain 587 molecule is known to be up to $2 \%$, with the developed CCS predictive model, the maximum deviation 588 at the $95 \%$ confidence interval was only $6 \%$. Mollerup et al. [127] were able to reduce the deviation 589 in the predicted CCS to a 4\%, consequently increasing the accuracy of the model. In the case of the 590 predictor model developed by Zhou et al. [128], support vector regression was applied to the 591 development of predictive models for different molecular adducts with median relative errors of 592 approximately 3\%. Regardless of the predictive model applied for the prediction of CCS, the utilization 593 of these strategies facilitates the tentative identification of NPS in suspect screening strategies [125], 594 especially when combined with RT and MS fragmentation predictive tools. 


\section{Future perspectives}

596 The determination of NPS in pooled urine and urban wastewater has shown several challenges due to 597 distinct factors as discussed in this manuscript. Current analytical instrumentation based on LC 598 combined with LRMS and HRMS and the application of complementary data acquisition workflows 599 and data exploration approaches helps to circumvent or confront certain barriers. However, more 600 research related to NPS biomarkers is required and several trends in analytical chemistry, which is 601 under continuous development, can be highlighted:

602

603 i. NPS biomarker selection. The high number of existing NPS and the constant introduction of new

ii. Sample collection, storage and treatment of pooled urine and wastewater is pivotal for getting monitoring of all NPS is complex and efforts could therefore be initially focused on NPS which are relatively high-dosed or frequently consumed and excreted (partly) unchanged such as amphetamine-like substances and cathinones. Especially since scant information on NPS pharmacokinetics is currently available, which complicates the choice of suitable biomarkers (parent substance or urinary metabolites) $[129,130]$. This is particularly relevant for synthetic cannabinoids and compounds like NBOMes that are highly metabolized in the human body $[42,131,132]$ and for synthetic opioids that are consumed at very low doses [39], leading in both cases to very low concentration levels of the corresponding biomarkers in urine and, consequently, in wastewater. However, there are some published works on the metabolism of NPS [80-84] and different computational tools exist that predicts the metabolic fate of chemicals $[86,87]$. Although the proposed metabolites therein are generally not commercially available for quantitative target monitoring, these compounds should be included within screening databases as well as aiding in retrospective data analysis to ensure that the most appropriate analytical targets are investigated. meaningful information on NPS use. Pooled urine analysis of samples collected from portable toilets and urinals give an informative snapshot of the NPS used, but is often limited to men only and it is difficult to extrapolate results to the total number of toilet users. All-gender toilets with an improved design, complying specific technical requirements like a flushing mechanism and a visitor counter could circumvent these limitations in future studies. Currently, daily composite wastewater samples are more representative and analysis provides population-normalized quantitative information on NPS. A best practice protocol to collect representative wastewater samples of an entire community is available [32] to ensure the comparability of results from different countries. However, wastewater is more diluted compared to pooled urine resulting in 
lower concentrations, which may complicate the detection of some NPS. Passive sampling increases the possibility to detect substances with low prevalence of use, because of the sampling and concentration of analytes over a longer period of time. Yet, passive sampling also merely gives a snapshot and has several limitations that need to be overcome or optimized as previously described. Recent developments, using diffusive gradients in thin films which, in contrast to conventional samplers, consist of a diffusive and binding gel and are exposed to the medium, are less dependent to hydrodynamic condition (e.g. flow rates) and can hence overcome some of the limitations encountered with conventional passive samplers $[133,134]$.

A relevant requirement for an NPS biomarker is its stability in pooled urine and wastewater in order to avoid any loss that can prevent detecting its use. Further work need to be addressed to test biomarkers stability and potential degradation or transformation in raw wastewater and urine [39-41,94]. Until more information is available, it is recommendable to store samples in the dark at $-20^{\circ} \mathrm{C}$ directly after sample collection in order to minimize possible degradation. Sample treatment is very important to improve detection. However, a versatile sample treatment to retaining a wide range of NPS is not always feasible and specific treatments for certain NPS classes such as synthetic cannabinoids and synthetic opioids (i.e. high potency NPS such as fentanyl) need to be developed.

iii. Good chromatographic separation might seem less important when coupled to highly sensitive and selective mass spectrometers, although it can be essential in the detection and identification of NPS. Taking into account the many isomers or structurally related compounds and the often strong matrix effects, more effort could be put into chromatographic separation in future work. HILIC and enantiomeric analysis have demonstrated a strong potential to move a step forward into a more comprehensive determination of NPS in wastewater and pooled urine. Capillary chromatography and UHPSFC-MS/MS have also been explored. Yet, some concerns have also been raised related to the robustness of the technique to routinely analyze complex matrices. Future developments in terms of more robust column chemistries will open a new scenario for the monitoring of NPS. Additionally, UHPSFC has the potential to combine the advantages of LC and GC, thus improving analytical capabilities of laboratories dealing with the determination of NPS.

Highly sensitive targeted methodologies based on LRMS will continue to play an important role in monitoring NPS use, particularly for those compounds which have established a niche market and/or are highly potent and require low detection limits. In addition, complementary suspect screening approaches based on large home-made databases, including many substances for which reference standards are not available, will remain the common practice for the foreseeable 
future. Furthermore, the improved sensitivity and quantitative capabilities of HRMS instruments

664 combined to multi-stage off-line or on-line solid-phase extraction allow achieving targeted

665 quantitative and qualitative screening analyses in a single run, thus overcoming the need of having

666 two distinct instruments/methods [27]. Similarly, machine learning algorithms used to relate peak

667 area of features recorded in HRMS analyses, chromatographic and mass spectrometric conditions

668 to concentrations, might overcome the need for reference standards to obtain an (indicative)

669 information about analyte concentrations in measured samples [135]. Qualitative information

670 about the presence or absence of given NPS in wastewater is informative and studies have shown

671 some spatial and temporal trends $[23,27,136]$, but only quantitative data can provide absolute

672 comparisons by showing changes in community prevalence through concentrations or mass loads.

673 v. Non-target screening remains predominantly unexplored for the identification of NPS in pooled 674 urine or wastewater. A genuine non-target screening without any selection of analytes to be 675 searched is a very challenging and time consuming process and a more successful strategy would 676 be the application of non-target screening directed towards the discovery of compounds 677 structurally related to known NPS. In this case, the higher concentrations generally present in 678 pooled urine makes this matrix most interesting for this approach. The expected improvements 679 for the forthcoming years in the mass-resolving power of HRMS instruments in combination with 680 higher scan-speed will allow the acquisition at higher mass resolution with more efficient 681 chromatography. This development in instrumentation will improve sensitivity and can also be 682 very useful to differentiate between isobaric compounds (i.e. compounds with the same nominal 683 mass but different chemical formula and thus different exact mass). Moreover, improved mass 684 resolving power does not only improve the separation of parent compounds, but can also help 685 finding characteristic fragment ions and gain confidence in the obtain identification. Furthermore, 686 improvements in software tools for peak picking and data deconvolution (i.e. the capability to find 687 chromatographic peaks of compounds and to obtain high quality spectra) will aid to a successful 688 identification of NPS, but the knowledge of basic rules in mass fragmentation and thus the 689 expertise of the mass spectrometrists should not be overlooked in both suspect and non-target 690 screening.

691 vi. The rapid transience of NPS in the drug market as well as the limited availability of reference 692 standards for both NPS and known metabolites poses an analytical challenge for the full 693 confirmation of substances detected. Therefore, the development and continuous updating of 694 collaborative and public NPS mass spectral databases will smooth the identification process since 695 contributors and users to those databases will have access to empirical information without the 696 need of having the reference standards in their own laboratories. Hence, the number of false 
697 positive identification (based on suspect and non-target screening) will be reduced since tentative 698 identifications will be supported by empirical data from other researchers.

699 vii. As is the case with online databases, prediction tools ease the tentative identification of NPS. The development of metabolic, RT and CCS predictive models represent a turning point in the investigation of NPS. The continual development of more accurate and refined predictive models will make prediction tools even more powerful for the application of NPS consumption particularly the complexity associated with structural similarities among NPS families. The small differences in the chemical backbone for most NPS classes and consequently similar physicochemical properties often make the current predictive tools less than ideal due to the analogous outcome obtained from the prediction.

707 viii.

Retrospective analysis will continue to play an important role in uncovering trends in NPS consumption. HRMS analyses allow analysts to continually explore samples, without the time expense associate with re-extracting and re-analyzing samples. Reprocessing samples should be performed periodically, which can be a laborious task. Nevertheless, it is an interesting tool, as 'new' NPS and metabolites are found, standards become more available and predictive techniques become more commonplace, retrospective analyses can be performed to better reveal community use of NPS.

Ion mobility separation coupled to HRMS has arisen as a useful technique and it is expected that it will gain in popularity. The cleaner and higher-quality mass spectra as well as the increased sensitivity of the instruments facilitates the identification process of NPS at low concentration levels and in complex wastewater or pooled urine samples. Future improvements will be related to the resolution of IMS instrument to enhance the separation of isobaric or isomeric substances that cannot be previously resolved by chromatography. 


\section{Conclusions}

721 Comprehensive analytical strategies can be applied to investigate NPS in pooled urine and 722 wastewater, from quantification of target biomarkers to the detection and (tentative) identification 723 of new substances and metabolites. The investigation of NPS in pooled urine and wastewater is a 724 subject of current interest because, integrated with additional epidemiological information, it can be 725 a useful tool for a comprehensive assessment of NPS use. In this context, data triangulation with 726 traditional indicators, such as public surveys, online forums, data of drug testing services, police 727 seizures and forensic analyses, is pivotal to gauge community consumption. Thus, the analysis of 728 pooled urine and wastewater can complement other data and provide a more complete picture of 729 community consumption.

730

731 Acknowledgements

732 The authors acknowledge EuSeME (project number 861602) funded by the European Union's Justice 733 Programme - Drugs Policy Initiatives, and NPS-Euronet (HOME/2014/JDRUG/AG/DRUG/7086) funded 734 with support from the European Commission. This communication reflects the views only of the 735 authors, and the European Commission cannot be held responsible for any use that may be made of 736 the information contained therein. Alberto Celma acknowledges the Spanish Ministry for Economy 737 and Competitiveness for his pre-doctoral grant (BES-2016-076914). Richard Bade acknowledges the 738 financial support of the Thyne Reid Foundation. The authors also acknowledge Juan Vicente Sancho 739 of the Research Institute for Pesticides and Water for his help and fruitful discussions, Florenci Vicent 740 González Adelantado and Lledo Bou-Iserte of the Department of Inorganic and Organic Chemistry, 741 University Jaume I (Spain) for the synthesis of $\alpha$-methyltryptamine. 


\section{References}

[1] European Monitoring Centre for Drugs and Drug Addiction, European Drug Report 2019: Trends and Developments, Lisbon, 2019. http://www.emcdda.europa.eu/system/files/publications/4541/TDAT17001ENN.pdf_en.

[2] United Nations Office on Drugs and Crime, Analysis of drug markets. World Drug Report 2018, 2018. doi:10.18356/dc023cb1-en.

[3] R. Bade, P. Stockham, B. Painter, A. Celma, L. Bijlsma, F. Hernandez, J.M. White, C. Gerber, Investigating the appearance of new psychoactive substances in South Australia using wastewater and forensic data, Drug Test. Anal. 11 (2019) 250-256. doi:10.1002/dta.2484.

[4] B. Hughes, J. Matias, P. Griffiths, Inconsistencies in the assumptions linking punitive sanctions and use of cannabis and new psychoactive substances in Europe, Addiction. (2018) 21552157. doi:10.1111/add.14372.

[5] J.B. Zawilska, "Legal Highs" - An emerging epidemic of novel psychoactive substances, 1st ed., Elsevier Inc., 2015. doi:10.1016/bs.irn.2015.02.009.

[6] A.J. Krotulski, D.M. Papsun, M. Friscia, J.L. Swartz, B.D. Holsey, B.K. Logan, Fatality following ingestion of tetrahydrofuranylfentanyl, U-49900 and methoxy-phencyclidine, J. Anal. Toxicol. 42 (2018) e27-e32. doi:10.1093/jat/bkx092.

[7] European Monitoring Centre for Drugs and Drug Addiction, EMCDDA: The EU early warning system, Eur. Monit. Cent. Drugs Drugs Addict. (2018).

http://www.emcdda.europa.eu/themes/new-drugs/early-warning (accessed October 15, 2019).

[8] R.A.S. Couto, L.M. Gonçalves, F. Carvalho, J.A. Rodrigues, C.M.P. Rodrigues, M.B. Quinaz, The Analytical Challenge in the Determination of Cathinones, Key-Players in the Worldwide Phenomenon of Novel Psychoactive Substances, Crit. Rev. Anal. Chem. 48 (2018) 372-390. doi:10.1080/10408347.2018.1439724.

[9] V. Angerer, L. Mogler, J.P. Steitz, P. Bisel, C. Hess, C.T. Schoeder, C.E. Müller, L.M. Huppertz, F. Westphal, J. Schäper, V. Auwärter, Structural characterization and pharmacological evaluation of the new synthetic cannabinoid CUMYL-PEGACLONE, Drug Test. Anal. 10 (2018) 597-603. doi:10.1002/dta.2237.

[10] N. Uchiyama, Y. Shimokawa, M. Kawamura, R. Kikura-Hanajiri, T. Hakamatsuka, Chemical analysis of a benzofuran derivative, 2-(2-ethylaminopropyl) benzofuran (2-EAPB), eight synthetic cannabinoids, five cathinone derivatives, and five other designer drugs newly detected in illegal products, Forensic Toxicol. 32 (2014) 266-281. doi:10.1007/s11419-0140238-5.

[11] L. Bijlsma, B. Miserez, M. Ibáñez, C. Vicent, E. Guillamón, J. Ramsey, F. Hernández, Identification and characterization of a novel cathinone derivative 1-(2,3-dihydro-1H-inden-5yl)-2-phenyl-2-(pyrrolidin-1-yl)-ethanone seized by customs in Jersey, Forensic Toxicol. 34 (2016) 144-150. doi:10.1007/s11419-015-0299-0.

[12] E. Partridge, S. Trobbiani, P. Stockham, T. Scott, C. Kostakis, A Validated Method for the Screening of 320 Forensically Significant Compounds in Blood by LC/QTOF, with Simultaneous Quantification of Selected Compounds, J. Anal. Toxicol. 42 (2018) 220-231. doi:10.1093/jat/bkx108. 
[13] M.R. Meyer, H.H. Maurer, LC coupled to low- and high-resolution mass spectrometry for new psychoactive substance screening in biological matrices - Where do we stand today?, Anal. Chim. Acta. 927 (2016) 13-20. doi:10.1016/j.aca.2016.04.046.

[14] D. Pasin, A. Cawley, S. Bidny, S. Fu, Current applications of high-resolution mass spectrometry for the analysis of new psychoactive substances: a critical review, Anal. Bioanal. Chem. 409 (2017) 5821-5836. doi:10.1007/s00216-017-0441-4.

[15] I. González-Mariño, E. Gracia-Lor, N.I. Rousis, E. Castrignanò, K. V. Thomas, J.B. Quintana, B. Kasprzyk-Hordern, E. Zuccato, S. Castiglioni, Wastewater-Based Epidemiology To Monitor Synthetic Cathinones Use in Different European Countries, Environ. Sci. Technol. 50 (2016) 10089-10096. doi:10.1021/acs.est.6b02644.

[16] C. Ort, L. Bijlsma, S. Castiglioni, A. Covaci, P. de Voogt, E. Emke, F. Hernández, M. Reid, A.L.N. van Nuijs, K. V. Thomas, B. Kasprzyk-Hordern, Wastewater Analysis for Community-Wide Drugs Use Assessment, in: H.H. Maurer, S.D. Brandt (Eds.), Handb. Exp. Pharmacol., Springer Berlin Heidelberg, 2018: pp. 1-24. doi:10.1007/164_2018_111.

[17] L. Bijlsma, A. Celma, F.J. López, F. Hernández, Monitoring new psychoactive substances use through wastewater analysis: current situation, challenges and limitations, Curr. Opin. Environ. Sci. Heal. 9 (2019) 1-12. doi:10.1016/j.coesh.2019.03.002.

[18] J.R.H. Archer, P.I. Dargan, S. Hudson, D.M. Wood, Analysis of anonymous pooled urine from portable urinals in central london confirms the significant use of novel psychoactive substances, QJM An Int. J. Med. 106 (2013) 147-152. doi:10.1093/qjmed/hcs219.

[19] J.R.H. Archer, S. Hudson, O. Jackson, T. Yamamoto, C. Lovett, H.M. Lee, S. Rao, L. Hunter, P.I. Dargan, D.M. Wood, Analysis of anonymized pooled urine in nine UK cities: Variation in classical recreational drug, novel psychoactive substance and anabolic steroid use, QJM An Int. J. Med. 108 (2015) 929-933. doi:10.1093/qjmed/hcv058.

[20] J. Kinyua, N. Negreira, B. Miserez, A. Causanilles, E. Emke, L. Gremeaux, P. de Voogt, J. Ramsey, A. Covaci, A.L.N. van Nuijs, Qualitative screening of new psychoactive substances in pooled urine samples from Belgium and United Kingdom, Sci. Total Environ. 573 (2016) 15271535. doi:10.1016/j.scitotenv.2016.08.124.

[21] J.R.H. Archer, P.I. Dargan, H.M.D. Lee, S. Hudson, D.M. Wood, Trend analysis of anonymised pooled urine from portable street urinals in central London identifies variation in the use of novel psychoactive substances, Clin. Toxicol. 52 (2014) 160-165. doi:10.3109/15563650.2014.885982.

[22] H. Gjerde, L. Gjersing, J.A. Baz-Lomba, L. Bijlsma, N. Salgueiro-González, H. Furuhaugen, A.L. Bretteville-Jensen, F. Hernández, S. Castiglioni, E. Johanna Amundsen, E. Zuccato, Drug Use by Music Festival Attendees: A Novel Triangulation Approach Using Self-Reported Data and Test Results of Oral Fluid and Pooled Urine Samples, Subst. Use Misuse. 0 (2019) 1-11. doi:10.1080/10826084.2019.1646285.

[23] L. Bijlsma, A. Celma, S. Castiglioni, N. Salgueiro-González, L. Bou-Iserte, J.A.J.A. Baz-Lomba, M.J.M.J. Reid, M.J.M.J. Dias, A. Lopes, J. Matias, L. Pastor-Alcañiz, J. Radonic, M.T. Sekulic, T. Shine, A.L.N.A.L.N. van Nuijs, F. Hernández, E. Zuccato, J. Radonić, M. Turk Sekulic, T. Shine, A.L.N.A.L.N. van Nuijs, F. Hernandez, E. Zuccato, Monitoring psychoactive substances use at six European festivals through wastewater and pooled urine analysis, Sci. Total Environ. 725 (2020). doi:10.1016/ j.scitotenv.2020.138376.

[24] L. Benaglia, R. Udrisard, A. Bannwarth, A. Gibson, F. Béen, F.Y. Lai, P. Esseiva, O. Delémont, Testing wastewater from a music festival in Switzerland to assess illicit drug use, Forensic Sci. 
Int. 309 (2020) 1-8. doi:10.1016/j.forsciint.2020.110148.

[25] J.R.H. Archer, P.I. Dargan, S. Hudson, S. Davies, M. Puchnarewicz, A.T. Kicman, J. Ramsey, F. Measham, M. Wood, A. Johnston, D.M. Wood, Taking the Pissoir - A novel and reliable way of knowing what drugs are being used in nightclubs, J. Subst. Use. 19 (2014) 103-107. doi:10.3109/14659891.2012.740139.

[26] A. Celma, J. V. Sancho, N. Salgueiro-González, S. Castiglioni, E. Zuccato, F. Hernández, L. Bijlsma, Simultaneous determination of new psychoactive substances and illicit drugs in sewage: Potential of micro-liquid chromatography tandem mass spectrometry in wastewaterbased epidemiology, J. Chromatogr. A. 1602 (2019) 300-309. doi:10.1016/j.chroma.2019.05.051.

[27] K. Diamanti, R. Aalizadeh, N. Alygizakis, A. Galani, M. Mardal, N.S. Thomaidis, Wide-scope target and suspect screening methodologies to investigate the occurrence of new psychoactive substances in influent wastewater from Athens, Sci. Total Environ. 685 (2019) 1058-1065. doi:10.1016/j.scitotenv.2019.06.173.

[28] C. Ort, A.L.N. van Nuijs, J.D. Berset, L. Bijlsma, S. Castiglioni, A. Covaci, P. de Voogt, E. Emke, D. Fatta-Kassinos, P. Griffiths, F. Hernández, I. González-Mariño, R. Grabic, B. KasprzykHordern, N. Mastroianni, A. Meierjohann, T. Nefau, M. Östman, Y. Pico, I. Racamonde, M. Reid, J. Slobodnik, S. Terzic, N. Thomaidis, K. V. Thomas, Spatial differences and temporal changes in illicit drug use in Europe quantified by wastewater analysis, Addiction. 109 (2014) 1338-1352. doi:10.1111/add.12570.

[29] I. González-Mariño, J.A. Baz-Lomba, N.A. Alygizakis, M.J. Andrés-Costa, R. Bade, A. Bannwarth, L.P. Barron, F. Been, L. Benaglia, J. Berset, L. Bijlsma, I. Bodík, A. Brenner, A.L. Brock, D.A. Burgard, E. Castrignanò, A. Celma, C.E. Christophoridis, A. Covaci, O. Delémont, P. Voogt, D.A. Devault, M.J. Dias, E. Emke, P. Esseiva, D. Fatta-Kassinos, G. Fedorova, K. Fytianos, C. Gerber, R. Grabic, E. Gracia-Lor, S. Grüner, T. Gunnar, E. Hapeshi, E. Heath, B. Helm, F. Hernández, A. Kankaanpaa, S. Karolak, B. Kasprzyk-Hordern, I. Krizman-Matasic, F.Y. Lai, W. Lechowicz, A. Lopes, M. López de Alda, E. López-García, A.S.C.C. Löve, N. Mastroianni, G.L. McEneff, R. Montes, K. Munro, T. Nefau, H. Oberacher, J.W. O’Brien, R. Oertel, K. Olafsdottir, Y. Picó, B.G. Plósz, F. Polesel, C. Postigo, J.B. Quintana, P. Ramin, M.J. Reid, J. Rice, R. Rodil, N. Salgueiro-González, S. Schubert, I. Senta, S.M. Simões, M.M. Sremacki, K. Styszko, S. Terzic, N.S. Thomaidis, K. V. Thomas, B.J. Tscharke, R. Udrisard, A.L.N. Nuijs, V. Yargeau, E. Zuccato, S. Castiglioni, C. Ort, Spatio-temporal assessment of illicit drug use at large scale: evidence from 7 years of international wastewater monitoring, Addiction. 115 (2020) 109-120. doi:10.1111/add.14767.

[30] E. Zuccato, C. Chiabrando, S. Castiglioni, R. Bagnati, R. Fanelli, Estimating community drug abuse by wastewater analysis, Environ. Health Perspect. 116 (2008) 1027-1032. doi:10.1289/ehp.11022.

[31] S. Castiglioni, L. Bijlsma, A. Covaci, E. Emke, F. Hernández, M. Reid, C. Ort, K. V. Thomas, A.L.N. Van Nuijs, P. De Voogt, E. Zuccato, Evaluation of uncertainties associated with the determination of community drug use through the measurement of sewage drug biomarkers, Environ. Sci. Technol. 47 (2013) 1452-1460. doi:10.1021/es302722f.

[32] European Monitoring Centre for Drugs and Drug Addiction, Assessing illicit drugs in wastwater, EMCDDA Ins, Publications Office of the European Union, Luxembourg, 2016. doi:10.2810/017397.

[33] J.A. Baz-Lomba, C. Harman, M. Reid, K. V. Thomas, Passive sampling of wastewater as a tool for the long-term monitoring of community exposure: Illicit and prescription drug trends as a 
proof of concept, Water Res. 121 (2017) 221-230. doi:10.1016/j.watres.2017.05.041.

[34] C. Harman, I.J. Allan, E.L.M. Vermeirssen, Calibration and use of the polar organic chemical integrative sampler-a critical review, Environ. Toxicol. Chem. 31 (2012) 2724-2738. doi:10.1002/etc.2011.

[35] P.O.M. Gundersen, O. Spigset, M. Josefsson, Screening, quantification, and confirmation of synthetic cannabinoid metabolites in urine by UHPLC-QTOF-MS, Drug Test. Anal. 11 (2019) 51-67. doi:10.1002/dta.2464.

[36] K.A. Alsenedi, C. Morrison, Determination and long-term stability of twenty-nine cathinones and amphetamine-type stimulants (ATS) in urine using gas chromatography-mass spectrometry, J. Chromatogr. B. 1076 (2018) 91-102. doi:10.1016/j.jchromb.2018.01.027.

[37] P. Adamowicz, A. Malczyk, Stability of synthetic cathinones in blood and urine, Forensic Sci. Int. 295 (2019) 36-45. doi:10.1016/j.forsciint.2018.12.001.

[38] M. Pettersson Bergstrand, O. Beck, A. Helander, Urine analysis of 28 designer benzodiazepines by liquid chromatography-high-resolution mass spectrometry, Clin. Mass Spectrom. 10 (2018) 25-32. doi:10.1016/j.clinms.2018.08.004.

[39] R. Bade, A. Abdelaziz, L. Nguyen, A.J. Pandopulos, J.M. White, C. Gerber, Determination of 21 synthetic cathinones, phenethylamines, amphetamines and opioids in influent wastewater using liquid chromatography coupled to tandem mass spectrometry, Talanta. 208 (2020). doi:10.1016/j.talanta.2019.120479.

[40] R. Bade, L. Bijlsma, J. V. Sancho, J.A. Baz-Lomba, S. Castiglioni, E. Castrignanò, A. Causanilles, E. Gracia-Lor, B. Kasprzyk-Hordern, J. Kinyua, A.K. McCall, A.L.N. van Nuijs, C. Ort, B.G. Plósz, P. Ramin, N.I. Rousis, Y. Ryu, K. V. Thomas, P. de Voogt, E. Zuccato, F. Hernández, Liquid chromatography-tandem mass spectrometry determination of synthetic cathinones and phenethylamines in influent wastewater of eight European cities, Chemosphere. 168 (2017) 1032-1041. doi:10.1016/j.chemosphere.2016.10.107.

[41] I. Senta, I. Krizman, M. Ahel, S. Terzic, Multiresidual analysis of emerging amphetamine-like psychoactive substances in wastewater and river water, J. Chromatogr. A. 1425 (2015) 204212. doi:10.1016/j.chroma.2015.11.043.

[42] M.J. Reid, L. Derry, K. V. Thomas, Analysis of new classes of recreational drugs in sewage: Synthetic cannabinoids and amphetamine-like substances, Drug Test. Anal. 6 (2014) 72-79. doi:10.1002/dta.1461.

[43] A.J. Pandopulos, R. Bade, J.W. O'Brien, B.J. Tscharke, J.F. Mueller, K. Thomas, J.M. White, C. Gerber, Towards an efficient method for the extraction and analysis of cannabinoids in wastewater, Talanta. 217 (2020) 121034. doi:10.1016/j.talanta.2020.121034.

[44] L.C.G. Hoegberg, C. Christiansen, J. Soe, R. Telving, M.F. Andreasen, D. Staerk, L.L. Christrup, K.T. Kongstad, Recreational drug use at a major music festival: trend analysis of anonymised pooled urine, Clin. Toxicol. 56 (2018) 245-255. doi:10.1080/15563650.2017.1360496.

[45] M. Mardal, J. Kinyua, P. Ramin, B. Miserez, A.L.N. Van Nuijs, A. Covaci, M.R. Meyer, Screening for illicit drugs in pooled human urine and urinated soil samples and studies on the stability of urinary excretion products of cocaine, MDMA, and MDEA in wastewater by hyphenated mass spectrometry techniques, Drug Test. Anal. 9 (2017) 106-114. doi:10.1002/dta.1957.

[46] V.L. Borova, P. Gago-Ferrero, C. Pistos, N.S. Thomaidis, Multi-residue determination of 10 selected new psychoactive substances in wastewater samples by liquid chromatographytandem mass spectrometry, Talanta. 144 (2015) 592-603. doi:10.1016/j.talanta.2015.06.080. 
[47] M.R. Boleda, M.T. Galceran, F. Ventura, Trace determination of cannabinoids and opiates in wastewater and surface waters by ultra-performance liquid chromatography-tandem mass spectrometry, J. Chromatogr. A. 1175 (2007) 38-48. doi:10.1016/j.chroma.2007.10.029.

[48] S. Castiglioni, E. Zuccato, E. Crisci, C. Chiabrando, R. Fanelli, R. Bagnati, Identification and measurement of illicit drugs and their metabolites in urban wastewater by liquid chromatography-tandem mass spectrometry, Anal. Chem. 78 (2006) 8421-8429. doi:10.1021/ac061095b.

[49] J. Gao, A. Banks, J. Li, G. Jiang, F.Y. Lai, J.F. Mueller, P.K. Thai, Evaluation of in-sewer transformation of selected illicit drugs and pharmaceutical biomarkers, Sci. Total Environ. 609 (2017) 1172-1181. doi:10.1016/j.scitotenv.2017.07.231.

[50] I. Krizman-Matasic, P. Kostanjevecki, M. Ahel, S. Terzic, Simultaneous analysis of opioid analgesics and their metabolites in municipal wastewaters and river water by liquid chromatography-tandem mass spectrometry, J. Chromatogr. A. 1533 (2018) 102-111. doi:10.1016/j.chroma.2017.12.025.

[51] M. Mardal, M.R. Meyer, Studies on the microbial biotransformation of the novel psychoactive substance methylenedioxypyrovalerone (MDPV) in wastewater by means of liquid chromatography-high resolution mass spectrometry/mass spectrometry, Sci. Total Environ. 493 (2014) 588-595. doi:10.1016/j.scitotenv.2014.06.016.

[52] N. Salgueiro-González, S. Castiglioni, E. Gracia-Lor, L. Bijlsma, A. Celma, R. Bagnati, F. Hernández, E. Zuccato, Flexible high resolution-mass spectrometry approach for screening new psychoactive substances in urban wastewater, Sci. Total Environ. 689 (2019) 679-690. doi:10.1016/j.scitotenv.2019.06.336.

[53] M.J. Andrés-Costa, V. Andreu, Y. Picó, Liquid chromatography-mass spectrometry as a tool for wastewater-based epidemiology: Assessing new psychoactive substances and other human biomarkers, TrAC - Trends Anal. Chem. 94 (2017) 21-38. doi:10.1016/j.trac.2017.06.012.

[54] C.E. O'Rourke, B. Subedi, Occurrence and Mass Loading of Synthetic Opioids, Synthetic Cathinones, and Synthetic Cannabinoids in Wastewater Treatment Plants in Four U.S. Communities, Environ. Sci. Technol. 54 (2020) 6661-6670. doi:10.1021/acs.est.0c00250.

[55] J. Kinyua, A. Covaci, W. Maho, A.K. Mccall, H. Neels, A.L.N. van Nuijs, Sewage-based epidemiology in monitoring the use of new psychoactive substances: Validation and application of an analytical method using LC-MS/MS, Drug Test. Anal. 7 (2015) 812-818. doi:10.1002/dta.1777.

[56] E. López-García, N. Mastroianni, C. Postigo, D. Barceló, M. López de Alda, A fully automated approach for the analysis of 37 psychoactive substances in raw wastewater based on on-line solid phase extraction-liquid chromatography-tandem mass spectrometry, J. Chromatogr. A. 1576 (2018) 80-89. doi:10.1016/j.chroma.2018.09.038.

[57] J.R.H. Archer, F. Mendes, S. Hudson, K. Layne, P.I. Dargan, D.M. Wood, Evaluation of longterm detection trends of new psychoactive substances in pooled urine from city street portable urinals (London, UK), Br. J. Clin. Pharmacol. 86 (2020) 517-527. doi:10.1111/bcp.14239.

[58] I. González-Mariño, K. V. Thomas, M.J. Reid, Determination of cannabinoid and synthetic cannabinoid metabolites in wastewater by liquid-liquid extraction and ultra-high performance supercritical fluid chromatography-tandem mass spectrometry, Drug Test. Anal. 10 (2018) 222-228. doi:10.1002/dta.2199. 
1001

1002

1003

1004

1005

1006

1007

1008
[59] I. Marchi, V. Viette, F. Badoud, M. Fathi, M. Saugy, S. Rudaz, J.L. Veuthey, Characterization and classification of matrix effects in biological samples analyses, J. Chromatogr. A. 1217 (2010) 4071-4078. doi:10.1016/j.chroma.2009.08.061.

[60] L. Bijlsma, E. Beltrán, C. Boix, J.V. Sancho, F. Hernández, Improvements in analytical methodology for the determination of frequently consumed illicit drugs in urban wastewater, Anal. Bioanal. Chem. 406 (2014) 4261-4272. doi:10.1007/s00216-014-7818-4.

[61] J.Y. Kim, S. Suh, J. Park, M.K. In, Simultaneous Determination of Amphetamine-Related New Psychoactive Substances in Urine by Gas Chromatography-Mass Spectrometry†, J. Anal. Toxicol. 42 (2018) 605-616. doi:10.1093/jat/bky037.

[62] L.A. Nisbet, F.M. Wylie, B.K. Logan, K.S. Scott, Gas Chromatography-Mass Spectrometry Method for the Quantitative Identification of 23 New Psychoactive Substances in Blood and Urine, J. Anal. Toxicol. 43 (2019) 346-352. doi:10.1093/jat/bky109.

[63] F. Hernández, S. Castiglioni, A. Covaci, P. de Voogt, E. Emke, B. Kasprzyk-Hordern, C. Ort, M. Reid, J. V. Sancho, K. V. Thomas, A.L.N. van Nuijs, E. Zuccato, L. Bijlsma, Mass spectrometric strategies for the investigation of biomarkers of illicit drug use in wastewater, Mass Spectrom. Rev. 37 (2018) 258-280. doi:10.1002/mas.21525.

[64] M. Concheiro, M. Castaneto, R. Kronstrand, M.A. Huestis, Simultaneous determination of 40 novel psychoactive stimulants in urine by liquid chromatography-high resolution mass spectrometry and library matching, J. Chromatogr. A. 1397 (2015) 32-42. doi:10.1016/j.chroma.2015.04.002.

[65] I. González-Mariño, V. Castro, R. Montes, R. Rodil, A. Lores, R. Cela, J.B. Quintana, Multiresidue determination of psychoactive pharmaceuticals, illicit drugs and related metabolites in wastewater by ultra-high performance liquid chromatography-tandem mass spectrometry, J. Chromatogr. A. 1569 (2018) 91-100. doi:10.1016/j.chroma.2018.07.045.

[66] E. Castrignanò, M. Mardal, A. Rydevik, B. Miserez, J. Ramsey, T. Shine, G.D. Panto, M.R. Meyer, B. Kasprzyk-Hordern, A new approach towards biomarker selection in estimation of human exposure to chiral chemicals: A case study of mephedrone, Sci. Rep. 7 (2017) 1-12. doi:10.1038/s41598-017-12581-3.

[67] E. Castrignanò, A. Lubben, B. Kasprzyk-Hordern, Enantiomeric profiling of chiral drug biomarkers in wastewater with the usage of chiral liquid chromatography coupled with tandem mass spectrometry, J. Chromatogr. A. 1438 (2016) 84-99. doi:10.1016/j.chroma.2016.02.015.

[68] E. Castrignanò, Z. Yang, R. Bade, J.A. Baz-Lomba, S. Castiglioni, A. Causanilles, A. Covaci, E. Gracia-Lor, F. Hernandez, J. Kinyua, A.-K. McCall, A.L.N. van Nuijs, C. Ort, B.G. Plósz, P. Ramin, N.I. Rousis, Y. Ryu, K. V. Thomas, P. de Voogt, E. Zuccato, B. Kasprzyk-Hordern, Enantiomeric profiling of chiral illicit drugs in a pan-European study, Water Res. 130 (2018) 151-160. doi:10.1016/j.watres.2017.11.051.

[69] B. Kasprzyk-Hordern, D.R. Baker, Estimation of community-wide drugs use via stereoselective profiling of sewage, Sci. Total Environ. 423 (2012) 142-150. doi:10.1016/j.scitotenv.2012.02.019.

[70] K.H. Storbeck, L. Gilligan, C. Jenkinson, E.S. Baranowski, J.L. Quanson, W. Arlt, A.E. Taylor, The utility of ultra-high performance supercritical fluid chromatography-tandem mass spectrometry (UHPSFC-MS/MS) for clinically relevant steroid analysis, J. Chromatogr. B Anal. Technol. Biomed. Life Sci. 1085 (2018) 36-41. doi:10.1016/j.jchromb.2018.03.033. 
[71] L. Nováková, A. Grand-Guillaume Perrenoud, I. Francois, C. West, E. Lesellier, D. Guillarme, Modern analytical supercritical fluid chromatography using columns packed with sub- $2 \mu \mathrm{m}$ particles: A tutorial, Anal. Chim. Acta. 824 (2014) 18-35. doi:10.1016/j.aca.2014.03.034.

[72] Å.M. Leere Øiestad, T. Berg, E. Eliassen, T. Wiklund, K. Sand, E. Leere Øiestad, Å.M.L. Øiestad, T. Berg, E. Eliassen, T. Wiklund, K. Sand, E. Leere Øiestad, Separation of isomers of new psychoactive substances and isotope-labeled amphetamines using UHPSFC-MS/MS and UHPLC-MS/MS, J. Liq. Chromatogr. Relat. Technol. 41 (2018) 391-400. doi:10.1080/10826076.2017.1388818.

[73] A.L.N. van Nuijs, A. Gheorghe, P.G. Jorens, K. Maudens, H. Neels, A. Covaci, Optimization, validation, and the application of liquid chromatography-tandem mass spectrometry for the analysis of new drugs of abuse in wastewater, Drug Test. Anal. 6 (2014) 861-867. doi:10.1002/dta.1460.

[74] A. Kankaanpää, K. Ariniemi, M. Heinonen, K. Kuoppasalmi, T. Gunnar, Use of illicit stimulant drugs in Finland: A wastewater study in ten major cities, Sci. Total Environ. 487 (2014) 696702. doi:10.1016/j.scitotenv.2013.11.095.

[75] European Commission, Commission Decision of 12 August 2002 implementing Council Directive $96 / 23 /$ EC concerning the performance of analytical methods and the interpretation of results (2002/657/EC), 2002.

[76] European Commission. Directorate General for Health and Food Safety., Guidance document on analytical quality control and method validation procedures for pesticide residue and analysis in food and feed. SANTE/11813/2017, 2017.

[77] M. Krauss, H. Singer, J. Hollender, LC-high resolution MS in environmental analysis: From target screening to the identification of unknowns, Anal. Bioanal. Chem. 397 (2010) 943-951. doi:10.1007/s00216-010-3608-9.

[78] T. Gao, P. Du, Z. Xu, X. Li, Occurrence of new psychoactive substances in wastewater of major Chinese cities, Sci. Total Environ. 575 (2017) 963-969. doi:10.1016/j.scitotenv.2016.09.152.

[79] B.J. Tscharke, C. Chen, J.P. Gerber, J.M. White, Temporal trends in drug use in Adelaide, South Australia by wastewater analysis, Sci. Total Environ. 565 (2016) 384-391. doi:10.1016/j.scitotenv.2016.04.183.

[80] M. Mardal, B. Miserez, R. Bade, T. Portolés, M. Bischoff, F. Hernández, M.R. Meyer, 3Fluorophenmetrazine, a fluorinated analogue of phenmetrazine: Studies on in vivo metabolism in rat and human, in vitro metabolism in human CYP isoenzymes and microbial biotransformation in Pseudomonas Putida and wastewater using GC and LC coupled to (HR, J. Pharm. Biomed. Anal. 128 (2016) 485-495. doi:10.1016/j.jpba.2016.06.011.

[81] F.Y. Lai, C. Erratico, J. Kinyua, J.F. Mueller, A. Covaci, A.L.N. van Nuijs, Liquid chromatographyquadrupole time-of-flight mass spectrometry for screening in vitro drug metabolites in humans: investigation on seven phenethylamine-based designer drugs, J. Pharm. Biomed. Anal. 114 (2015) 355-375. doi:10.1016/j.jpba.2015.06.016.

[82] A.T. Caspar, F. Westphal, M.R. Meyer, H.H. Maurer, LC-high resolution-MS/MS for identification of 69 metabolites of the new psychoactive substance 1-(4-ethylphenyl-)-N-[(2methoxyphenyl)methyl] propane-2-amine (4-EA-NBOMe) in rat urine and human liver 59 incubates and comparison of its screening power wit, Anal. Bioanal. Chem. 410 (2018) 897912. doi:10.1007/s00216-017-0526-0.

[83] P. Vervliet, O. Mortelé, C. Gys, M. Degreef, K. Lanckmans, K. Maudens, A. Covaci, A.L.N. van 
Nuijs, F.Y. Lai, Suspect and non-target screening workflows to investigate the in vitro and in vivo metabolism of the synthetic cannabinoid 5Cl-THJ-018, Drug Test. Anal. 11 (2019) 479491. doi:10.1002/dta.2508.

[84] X. Diao, M.A. Huestis, New synthetic cannabinoids metabolism and strategies to best identify optimal marker metabolites, Front. Chem. 7 (2019) 1-15. doi:10.3389/fchem.2019.00109.

[85] Y. Djoumbou-Feunang, J. Fiamoncini, A. Gil-de-la-Fuente, R. Greiner, C. Manach, D.S. Wishart, BioTransformer: a comprehensive computational tool for small molecule metabolism prediction and metabolite identification, J. Cheminform. 11 (2019) 2. doi:10.1186/s13321018-0324-5.

[86] S. Kern, K. Fenner, H.P. Singer, R.P. Schwarzenbach, J. Hollender, Identification of Transformation Products of Organic Contaminants in Natural Waters by Computer-Aided Prediction and High-Resolution Mass Spectrometry, Environ. Sci. Technol. 43 (2009) 70397046. doi:10.1021/es901979h.

[87] C. Hug, N. Ulrich, T. Schulze, W. Brack, M. Krauss, Identification of novel micropollutants in wastewater by a combination of suspect and nontarget screening, Environ. Pollut. 184 (2014) 25-32. doi:10.1016/j.envpol.2013.07.048.

[88] N.A. Alygizakis, S. Samanipour, J. Hollender, M. Ibáñez, S. Kaserzon, V. Kokkali, J.A. Van Leerdam, J.F. Mueller, M. Pijnappels, M.J. Reid, E.L. Schymanski, J. Slobodnik, N.S. Thomaidis, K. V. Thomas, Exploring the Potential of a Global Emerging Contaminant Early Warning Network through the Use of Retrospective Suspect Screening with High-Resolution Mass Spectrometry, Environ. Sci. Technol. 52 (2018) 5135-5144. doi:10.1021/acs.est.8b00365.

[89] L. Bijlsma, E. Emke, F. Hernández, P. De Voogt, Performance of the linear ion trap Orbitrap mass analyzer for qualitative and quantitative analysis of drugs of abuse and relevant metabolites in sewage water, Anal. Chim. Acta. 768 (2013) 102-110. doi:10.1016/j.aca.2013.01.010.

[90] T. Reemtsma, U. Berger, H.P.H. Arp, H. Gallard, T.P. Knepper, M. Neumann, J.B. Quintana, P. De Voogt, Mind the Gap: Persistent and Mobile Organic Compounds - Water Contaminants That Slip Through, Environ. Sci. Technol. 50 (2016) 10308-10315. doi:10.1021/acs.est.6b03338.

[91] J.A. Baz-Lomba, M.J. Reid, K. V. Thomas, Target and suspect screening of psychoactive substances in sewage-based samples by UHPLC-QTOF, Anal. Chim. Acta. 914 (2016) 81-90. doi:10.1016/j.aca.2016.01.056.

[92] Y. Picó, D. Barceló, Transformation products of emerging contaminants in the environment and high-resolution mass spectrometry: A new horizon, Anal. Bioanal. Chem. 407 (2015) 6257-6273. doi:10.1007/s00216-015-8739-6.

[93] Z. Qian, Z. Hua, C. Liu, W. Jia, Four types of cannabimimetic indazole and indole derivatives, ADB-BINACA, AB-FUBICA, ADB-FUBICA, and AB-BICA, identified as new psychoactive substances, Forensic Toxicol. 34 (2016) 133-143. doi:10.1007/s11419-015-0297-2.

[94] I. González-Mariño, E. Gracia-Lor, R. Bagnati, C.P.B. Martins, E. Zuccato, S. Castiglioni, Screening new psychoactive substances in urban wastewater using high resolution mass spectrometry, Anal. Bioanal. Chem. 408 (2016) 4297-4309. doi:10.1007/s00216-016-9521-0.

[95] H. Oberacher, K. Arnhard, Current status of non-targeted liquid chromatography-tandem mass spectrometry in forensic toxicology, TrAC Trends Anal. Chem. 84 (2016) 94-105. doi:10.1016/j.trac.2015.12.019. 
[96] X. Zhu, Y. Chen, R. Subramanian, Comparison of information-dependent acquisition, SWATH and MS All techniques in metabolite identification study employing ultrahigh-performance liquid chromatography-quadrupole time-of-flight mass spectrometry, Anal. Chem. 86 (2014) 1202-1209. doi:10.1021/ac403385y.

[97] A.T. Roemmelt, A.E. Steuer, T. Kraemer, Liquid Chromatography, in Combination with a Quadrupole Time-of-Flight Instrument, with Sequential Window Acquisition of All Theoretical Fragment-Ion Spectra Acquisition: Validated Quantification of 39 Antidepressants in Whole Blood As Part of a Simultane, Anal. Chem. 87 (2015) 9294-9301. doi:10.1021/acs.analchem.5b02031.

[98] J. Nácher-Mestre, M. Ibáñez, R. Serrano, C. Boix, L. Bijlsma, B.T. Lunestad, R. Hannisdal, M. Alm, F. Hernández, M.H.G. Berntssen, Investigation of pharmaceuticals in processed animal by-products by liquid chromatography coupled to high-resolution mass spectrometry, Chemosphere. 154 (2016) 231-239. doi:10.1016/j.chemosphere.2016.03.091.

[99] R. Bade, J.M. White, C. Gerber, Qualitative and quantitative temporal analysis of licit and illicit drugs in wastewater in Australia using liquid chromatography coupled to mass spectrometry, Anal. Bioanal. Chem. 410 (2018) 529-542. doi:10.1007/s00216-017-0747-2.

[100] R. Bade, B.J. Tscharke, J.M. White, S. Grant, J.F. Mueller, J. O’Brien, K. V. Thomas, C. Gerber, LC-HRMS suspect screening to show spatial patterns of New Psychoactive Substances use in Australia, Sci. Total Environ. 650 (2019) 2181-2187. doi:10.1016/j.scitotenv.2018.09.348.

[101] A. Urbas, T. Schoenberger, C. Corbett, K. Lippa, F. Rudolphi, W. Robien, NPS Data Hub: A webbased community driven analytical data repository for new psychoactive substances, Forensic Chem. 9 (2018) 76-81. doi:10.1016/j.forc.2018.05.003.

[102] M. Mardal, M.F. Andreasen, C.B. Mollerup, P. Stockham, R. Telving, N.S. Thomaidis, K.S. Diamanti, K. Linnet, P.W. Dalsgaard, HighResNPS.com: An Online Crowd-Sourced HR-MS Database for Suspect and Non-targeted Screening of New Psychoactive Substances, J. Anal. Toxicol. 43 (2019) 520-527. doi:10.1093/jat/bkz030.

[103] HighRes NPS Community, HighResNPS, HighResNPS. (n.d.). http://highresnps.forensic.ku.dk/.

[104] J.Z. Seither, R. Hindle, L.E. Arroyo-Mora, A.P. DeCaprio, Systematic analysis of novel psychoactive substances. I. Development of a compound database and HRMS spectral library, Forensic Chem. 9 (2018) 12-20. doi:10.1016/j.forc.2018.03.003.

[105] M. Mardal, S.S. Johansen, A.B. Davidsen, R. Telving, J.R. Jornil, P.W. Dalsgaard, J.B. Hasselstrøm, Å.M. Øiestad, K. Linnet, M.F. Andreasen, Postmortem analysis of three methoxyacetylfentanyl-related deaths in Denmark and in vitro metabolite profiling in pooled human hepatocytes, Forensic Sci. Int. 290 (2018) 310-317. doi:10.1016/j.forsciint.2018.07.020.

[106] H. Horai, M. Arita, S. Kanaya, Y. Nihei, T. Ikeda, K. Suwa, Y. Ojima, K. Tanaka, S. Tanaka, K. Aoshima, Y. Oda, Y. Kakazu, M. Kusano, T. Tohge, F. Matsuda, Y. Sawada, M.Y. Hirai, H. Nakanishi, K. Ikeda, N. Akimoto, T. Maoka, H. Takahashi, T. Ara, N. Sakurai, H. Suzuki, D. Shibata, S. Neumann, T. lida, K. Tanaka, K. Funatsu, F. Matsuura, T. Soga, R. Taguchi, K. Saito, T. Nishioka, MassBank: A public repository for sharing mass spectral data for life sciences, J. Mass Spectrom. 45 (2010) 703-714. doi:10.1002/jms.1777.

[107] Z. Qian, W. Jia, T. Li, Z. Hua, C. Liu, Identification of five pyrrolidinyl substituted cathinones and the collision-induced dissociation of electrospray-generated pyrrolidinyl substituted cathinones, Drug Test. Anal. 9 (2017) 778-787. doi:10.1002/dta.2035. 
[108] M. Ibáñez, J.V. Sancho, L. Bijlsma, A.L.N. van Nuijs, A. Covaci, F. Hernández, Comprehensive analytical strategies based on high-resolution time-of-flight mass spectrometry to identify new psychoactive substances, TrAC - Trends Anal. Chem. 57 (2014) 107-117. doi:10.1016/j.trac.2014.02.009.

[109] D. Zuba, K. Sekuła, A. Buczek, Identification and characterization of 2,5-dimethoxy-4-nitro- $\beta$ phenethylamine (2C-N) - A new member of 2C-series of designer drug, Forensic Sci. Int. 222 (2012) 298-305. doi:10.1016/j.forsciint.2012.07.006.

[110] S.P. Elliott, S.D. Brandt, S. Freeman, R.P. Archer, AMT (3-(2-aminopropyl)indole) and 5-IT (5(2-aminopropyl)indole): An analytical challenge and implications for forensic analysis, Drug Test. Anal. 5 (2013) 196-202. doi:10.1002/dta.1420.

[111] R. Aalizadeh, M.-C. Nika, N.S. Thomaidis, Development and application of retention time prediction models in the suspect and non-target screening of emerging contaminants, J. Hazard. Mater. 363 (2019) 277-285. doi:10.1016/j.jhazmat.2018.09.047.

[112] R. Bade, L. Bijlsma, T.H. Miller, L.P. Barron, J.V. Sancho, F. Hernández, Suspect screening of large numbers of emerging contaminants in environmental waters using artificial neural networks for chromatographic retention time prediction and high resolution mass spectrometry data analysis, Sci. Total Environ. 538 (2015) 934-941. doi:10.1016/j.scitotenv.2015.08.078.

[113] S. Wolf, S. Schmidt, M. Müller-Hannemann, S. Neumann, In silico fragmentation for computer assisted identification of metabolite mass spectra, BMC Bioinformatics. 11 (2010). doi:10.1186/1471-2105-11-148.

[114] C. Ruttkies, E.L. Schymanski, S. Wolf, J. Hollender, S. Neumann, MetFrag relaunched: Incorporating strategies beyond in silico fragmentation, J. Cheminform. 8 (2016) 1-16. doi:10.1186/s13321-016-0115-9.

[115] J.W. Lee, Basics of ion mobility mass spectrometry, Mass Spectrom. Lett. 8 (2017) 79-89. doi:10.5478/MSL.2017.8.4.79.

[116] J. Regueiro, N. Negreira, M.H.G. Berntssen, Ion-mobility-derived collision cross section as an additional identification point for multiresidue screening of pesticides in fish feed, Anal. Chem. 88 (2016) 11169-11177. doi:10.1021/acs.analchem.6b03381.

[117] L. Bijlsma, M.H.G. Berntssen, S. Merel, A Refined Nontarget Workflow for the Investigation of Metabolites through the Prioritization by in Silico Prediction Tools, Anal. Chem. 91 (2019) 6321-6328. doi:10.1021/acs.analchem.9b01218.

[118] A.S. Gelb, R.E. Jarratt, Y. Huang, E.D. Dodds, A study of calibrant selection in measurement of carbohydrate and peptide ion-neutral collision cross sections by traveling wave ion mobility spectrometry, Anal. Chem. 86 (2014) 11396-11402. doi:10.1021/ac503379e.

[119] G. Paglia, J.P. Williams, L. Menikarachchi, J.W. Thompson, R. Tyldesley-Worster, S. Halldórsson, O. Rolfsson, A. Moseley, D. Grant, J. Langridge, B.O. Palsson, G. Astarita, Ion mobility derived collision cross sections to support metabolomics applications, Anal. Chem. 86 (2014) 3985-3993. doi:10.1021/ac500405x.

[120] L. Fiebig, R. Laux, A collision cross section and exact ion mass database of the formulation constituents polyethylene glycol 400 and polysorbate 80, Int. J. Ion Mobil. Spectrom. 19 (2016) 131-137. doi:10.1007/s12127-016-0195-2.

[121] J. Hofmann, H.S. Hahm, P.H. Seeberger, K. Pagel, Identification of carbohydrate anomers using ion mobility-mass spectrometry, Nature. 526 (2015) 241-244. 
doi:10.1038/nature15388.

[122] J. Regueiro, A. Giri, T. Wenzl, Optimization of a Differential Ion Mobility SpectrometryTandem Mass Spectrometry Method for High-Throughput Analysis of Nicotine and Related Compounds: Application to Electronic Cigarette Refill Liquids, Anal. Chem. 88 (2016) 65006508. doi:10.1021/acs.analchem.6b01241.

[123] L. Bijlsma, R. Bade, A. Celma, L. Mullin, G. Cleland, S. Stead, F. Hernandez, J.V.J.V. Sancho, Prediction of Collision Cross-Section Values for Small Molecules: Application to Pesticide Residue Analysis, Anal. Chem. 89 (2017) 6583-6589. doi:10.1021/acs.analchem.7b00741.

[124] L. Bijlsma, J. V. Sancho, F. Hernández, W.M.A. Niessen, Fragmentation pathways of drugs of abuse and their metabolites based on QTOF MS/MS and MS E accurate-mass spectra, J. Mass Spectrom. 46 (2011) 865-875. doi:10.1002/jms.1963.

[125] R. Lian, F. Zhang, Y. Zhang, Z. Wu, H. Ye, C. Ni, X. Lv, Y. Guo, Ion mobility derived collision cross section as an additional measure to support the rapid analysis of abused drugs and toxic compounds using electrospray ion mobility time-of-flight mass spectrometry, Anal. Methods. 10 (2018) 749-756. doi:10.1039/C7AY02808C.

[126] C. Tejada-Casado, M. Hernández-Mesa, F. Monteau, F.J. Lara, M. del Olmo-Iruela, A.M. García-Campaña, B. Le Bizec, G. Dervilly-Pinel, Collision cross section (CCS) as a complementary parameter to characterize human and veterinary drugs, Anal. Chim. Acta. 1043 (2018) 52-63. doi:10.1016/j.aca.2018.09.065.

[127] C.B. Mollerup, M. Mardal, P.W. Dalsgaard, K. Linnet, L.P. Barron, Prediction of collision cross section and retention time for broad scope screening in gradient reversed-phase liquid chromatography-ion mobility-high resolution accurate mass spectrometry, J. Chromatogr. A. 1542 (2018) 82-88. doi:10.1016/j.chroma.2018.02.025.

[128] Z. Zhou, X. Shen, J. Tu, Z.J. Zhu, Large-scale prediction of collision cross-section values for metabolites in ion mobility-mass spectrometry, Anal. Chem. 88 (2016) 11084-11091. doi:10.1021/acs.analchem.6b03091.

[129] E. Gracia-Lor, S. Castiglioni, R. Bade, F. Been, E. Castrignanò, A. Covaci, I. González-Mariño, E. Hapeshi, B. Kasprzyk-Hordern, J. Kinyua, F.Y. Lai, T. Letzel, L. Lopardo, M.R. Meyer, J. O'Brien, P. Ramin, N.I. Rousis, A. Rydevik, Y. Ryu, M.M. Santos, I. Senta, N.S. Thomaidis, S. Veloutsou, Z. Yang, E. Zuccato, L. Bijlsma, Measuring biomarkers in wastewater as a new source of epidemiological information: Current state and future perspectives, Environ. Int. 99 (2017) 131-150. doi:10.1016/j.envint.2016.12.016.

[130] E. Gracia-Lor, E. Zuccato, S. Castiglioni, Refining correction factors for back-calculation of illicit drug use, Sci. Total Environ. 573 (2016) 1648-1659. doi:10.1016/j.scitotenv.2016.09.179.

[131] L. Bijlsma, R. Gil-Solsona, F. Hernández, J.V. Sancho, What about the herb? A new metabolomics approach for synthetic cannabinoid drug testing, Anal. Bioanal. Chem. 410 (2018) 5107-5112. doi:10.1007/s00216-018-1182-8.

[132] A.T. Caspar, S.D. Brandt, A.E. Stoever, M.R. Meyer, H.H. Maurer, Metabolic fate and detectability of the new psychoactive substances 2-(4-bromo-2,5-dimethoxyphenyl)- N- [(2methoxyphenyl)methyl]ethanamine (25B-NBOMe) and 2-(4-chloro-2,5-dimethoxyphenyl)- N[(2-methoxyphenyl)methyl] ethanamine (25C-NBOMe) in human and $r$, J. Pharm. Biomed. Anal. 134 (2017) 158-169. doi:10.1016/j.jpba.2016.11.040.

[133] E.D. Amato, A. Covaci, R.M. Town, J. Hereijgers, B. Bellekens, V. Giacometti, T. Breugelmans, M. Weyn, F. Dardenne, L. Bervoets, R. Blust, A novel active-passive sampling approach for 
measuring time-averaged concentrations of pollutants in water, Chemosphere. 209 (2018) 363-372. doi:10.1016/j.chemosphere.2018.06.079.

[134] Y. Zhang, T. Zhang, C. Guo, S. Hou, Z. Hua, J. Lv, Y. Zhang, J. Xu, Development and application of the diffusive gradients in thin films technique for simultaneous measurement of methcathinone and ephedrine in surface river water, Sci. Total Environ. 618 (2018) 284-290. doi:10.1016/j.scitotenv.2017.11.068.

[135] A. Kruve, Semi-quantitative non-target analysis of water with liquid chromatography/highresolution mass spectrometry: How far are we?, Rapid Commun. Mass Spectrom. 33 (2019) 54-63. doi:10.1002/rcm.8208.

[136] R. Bade, J.M. White, L. Nguyen, B.J. Tscharke, J.F. Mueller, J.W. O'Brien, K. V. Thomas, C. Gerber, Determining changes in new psychoactive substance use in Australia by wastewater analysis, Sci. Total Environ. 731 (2020) 139209. doi:10.1016/j.scitotenv.2020.139209. 


\section{Figure captions}

Figure 1: Identification of two co-eluting NPS, butyryl fentanyl $(\mathrm{m} / \mathrm{z} 351.2431)$ and furanylfentanyl ( $\mathrm{m} / \mathrm{z}$ 375.2067) in a spiked wastewater sample using Sequential Window Acquisition of all THeoretical fragment ion spectra (SWATH). (A) overlapping extraction ion chromatograms (XICs) of the two NPS with chromatographic peaks eluting at $12.50 \mathrm{~min}$ (top); full scan acquisition mass spectra with low collision energy (LE) (10 V) at retention time $12.50 \pm 0.10$ min (bottom). (B) SWATH mass window $\mathrm{m} / \mathrm{z}$ 340.2-357.4, XIC at $\mathrm{m} / \mathrm{z} 351.24$ (middle) and high collision energy (HE) mass spectra (bottom); (C) SWATH mass window $m / z$ 372.6-389.8, XIC at $\mathrm{m} / \mathrm{z} 375.21$ (middle) and HE mass spectra (bottom).

Figure 2: Tentative identification of 4 '-chloro- $\alpha$-pyrrolidinopropiophenone (4-chloro- $\alpha$-PPP) in a pooled urine sample. (A) Extracted ion chromatogram of 4-chloro- $\alpha$-PPP and ${ }^{37} \mathrm{Cl}$ isotope (top); Product ion mass spectra of $[\mathrm{M}+\mathrm{H}]^{+}$at $m / z 238.10$ (bottom). (B) Structure of 4-chloro- $\alpha$-PPP (top); Zoom in the range of fragment ion with $\mathrm{m} / \mathrm{z} 167$ at resolution (R) of 35.000 Full Width at Half Maximum (FWHM) (bottom).

Figure 3: Identification of $\alpha$-methyltryptamine in a raw wastewater sample using QTOF MS. (A) feature detection of $\mathrm{m} / \mathrm{z} 175.1235$ at $4.51 \mathrm{~min}$ (top, insert) together with the low collision energy (LE) spectra (top) and high collision energy (HE) spectra with emphasis on $m / z$ 130-145 (grey areas) (bottom); (B) Structure, fragment ions, LE and HE spectra of $\alpha$-methyltryptamine; (C) Structure, fragment ions, LE and HE spectra of 5-(2-aminopropyl)indole.

Figure 4: Identification of ketamine in a raw wastewater sample using IMS QTOF MS. (A) feature detection of $\mathrm{m} / \mathrm{z} 238.0993$ at $3.33 \mathrm{~min}$ and drift time (DT) $4.89 \mathrm{~ms}$, yellow arrow (top) (*70 $\mu \mathrm{s} / \mathrm{scan})$; co-eluting ions at $3.33 \mathrm{~min}$ illustrated as red or black dots and separated by DT. Blue highlighted areas are the DT ranges of $4.89 \pm 0.20 \mathrm{~ms}$ at $\mathrm{m} / \mathrm{z} 238.0993$ at low collision energy (LE) and high collision energy (HE) (bottom). (B) LE and HE mass spectra without IMS DT alignment (top); LE and HE mass spectra with IMS DT alignment (bottom). 


\section{Full scan at LE}

\section{$m / z$ 351.24 \pm 0.05 Da XIC butyryl fentanyl} $m / z$ 375.21 \pm 0.05 Da XIC furanylfentanyl
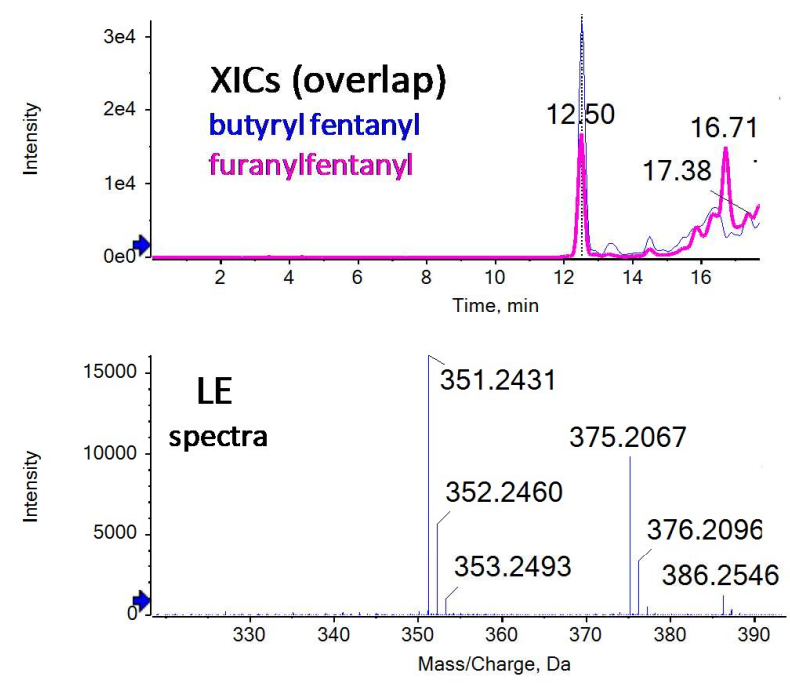

A

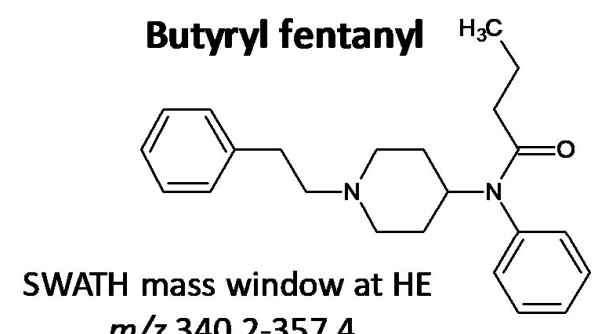

$m / z 340.2-357.4$
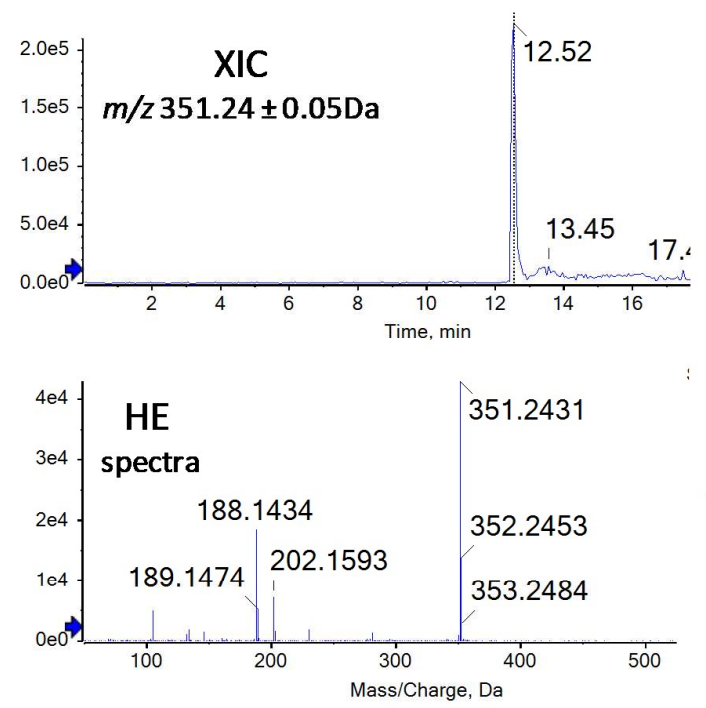

B

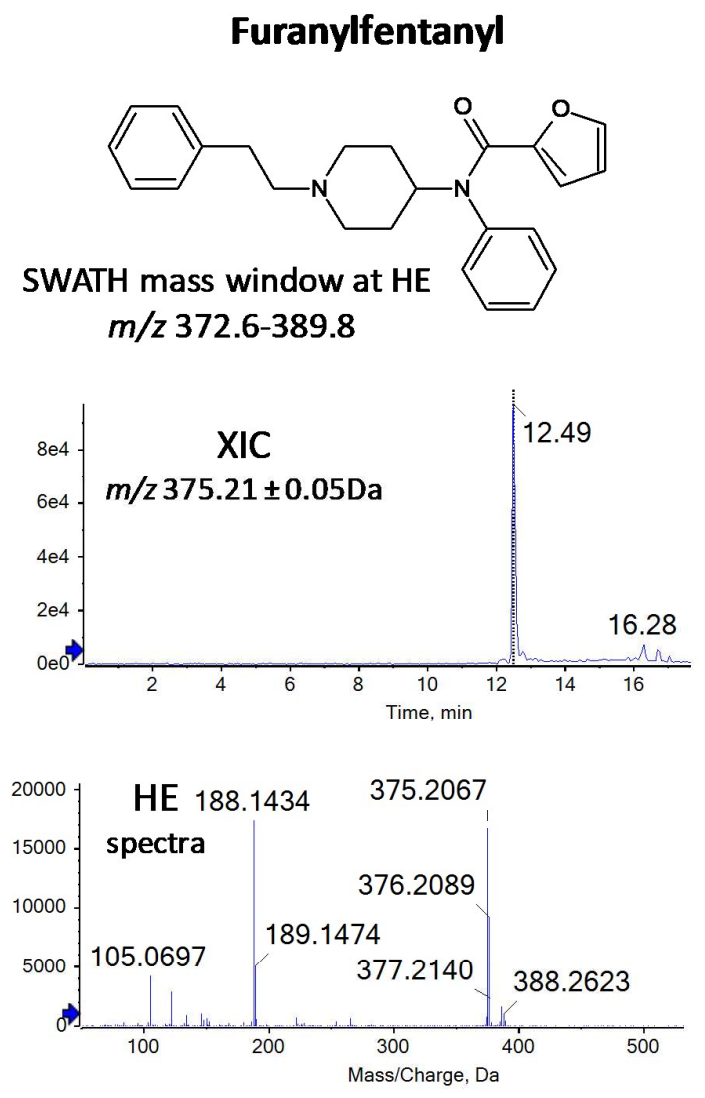

C

Figure 1 


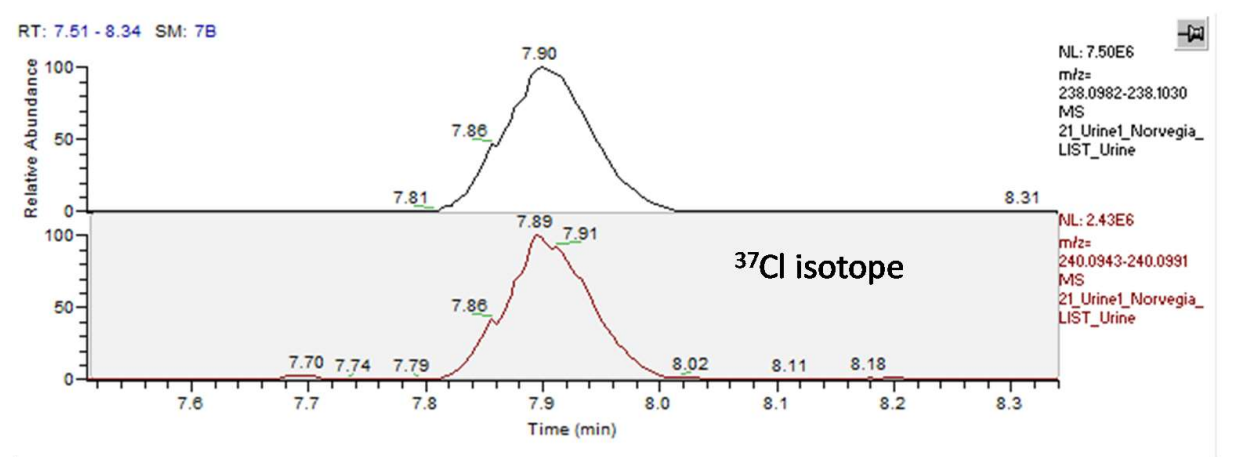

\section{4-chloro- $\alpha$-PPP}

Exact mass $[\mathrm{M}+\mathrm{H}]^{+}$ $238.0993(+0.8 \mathrm{ppm})$

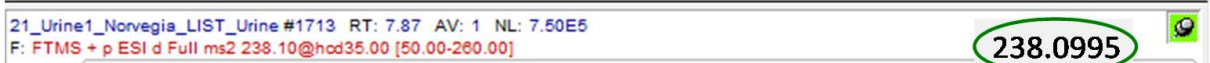

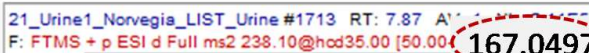

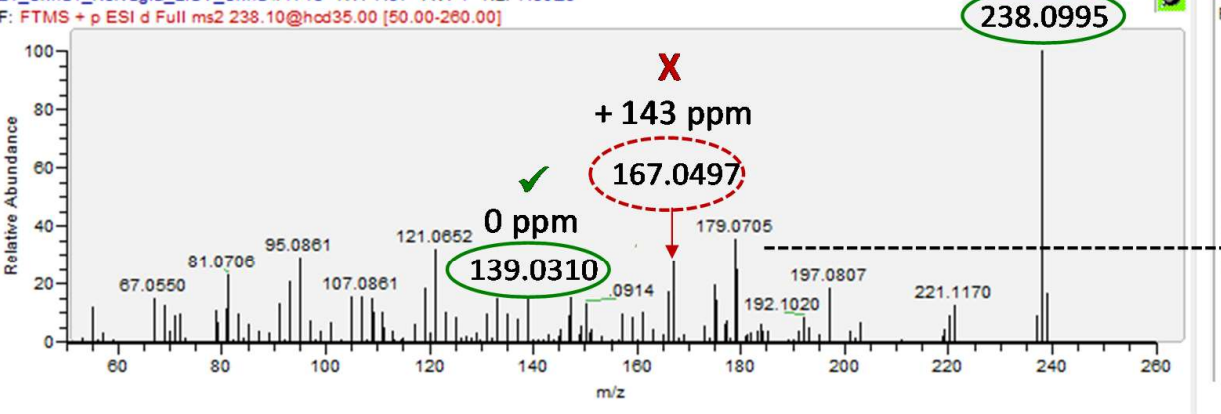

A

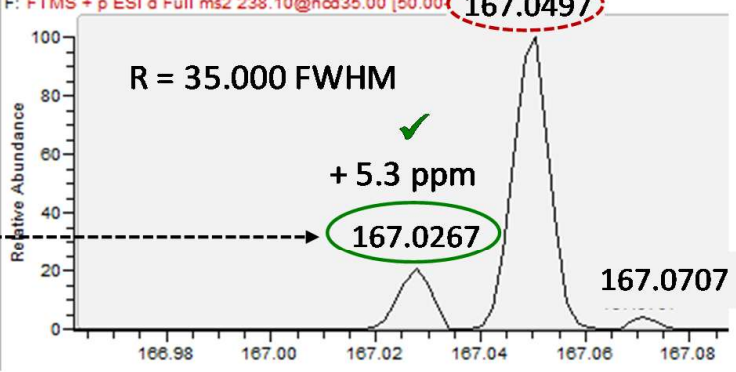

Figure 2 


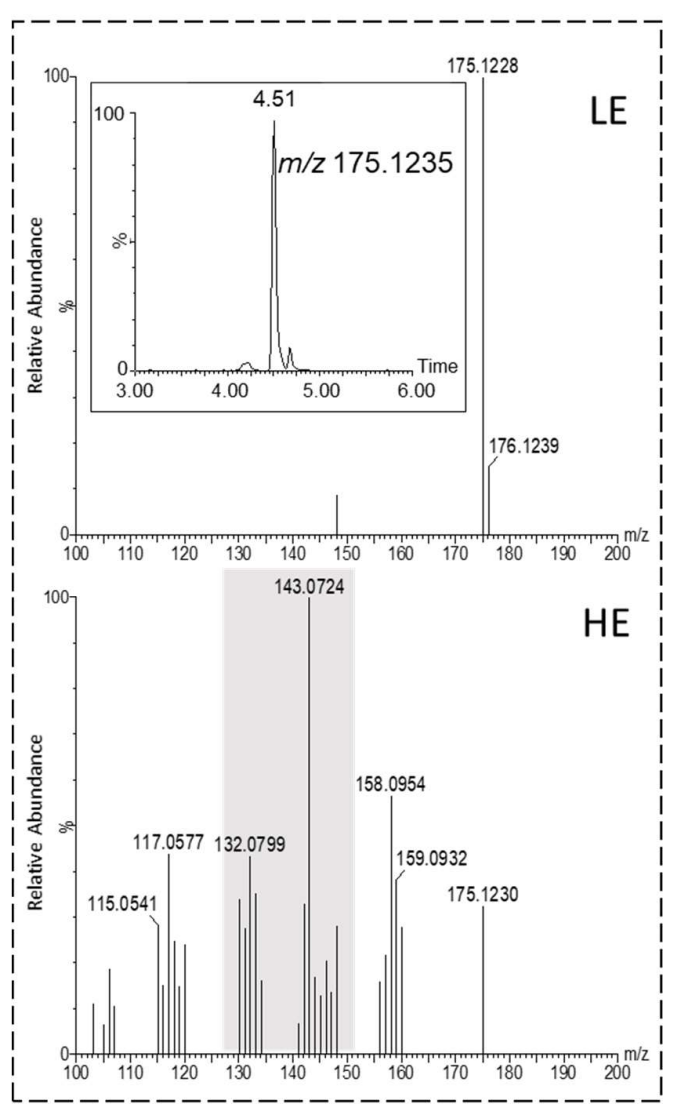

A

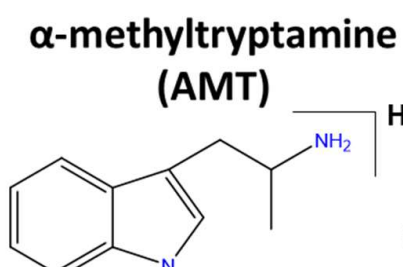

$\mathrm{C}_{11} \mathrm{H}_{15} \mathrm{~N}_{2}^{+}$ $\mathrm{m} / \mathrm{z} 175.1235$

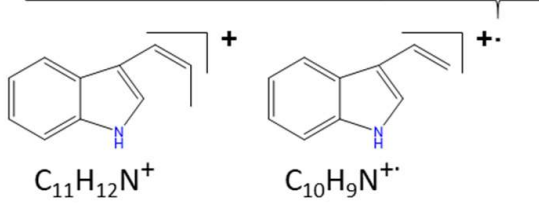

$\mathrm{m} / \mathrm{z} 158.0964 \mathrm{~m} / \mathrm{z} 143.0657$
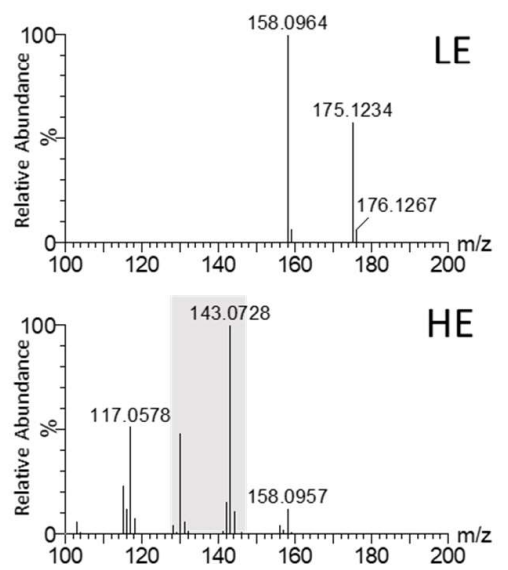

B 5-(2-aminopropyl)indole

(5-IT)

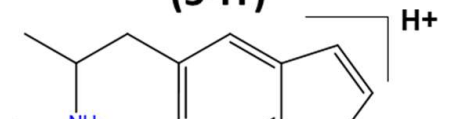

$\mathrm{NH}_{2}$

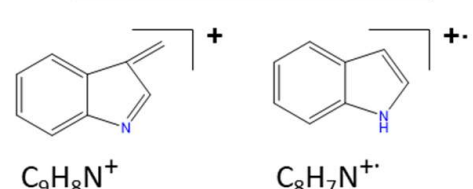

$\mathrm{m} / \mathrm{z} 130.0735 \mathrm{~m} / \mathrm{z} 117.0578$
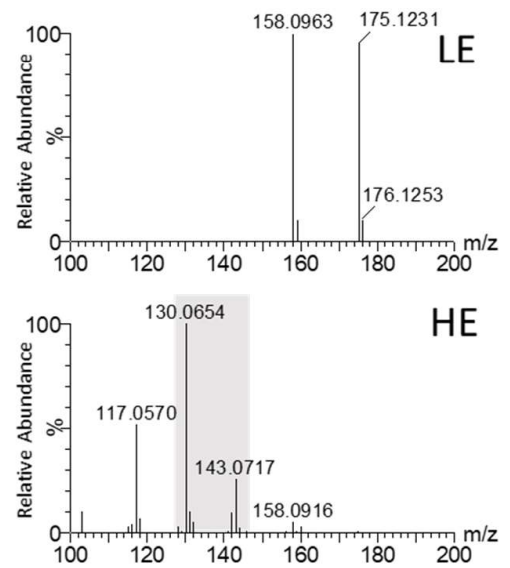

C 
Ketamine, RT=3.33 min, $m / z\left([\mathrm{M}+\mathrm{H}]^{+}\right)=238.0993, \mathrm{DT}=4.89 \mathrm{~ms}$

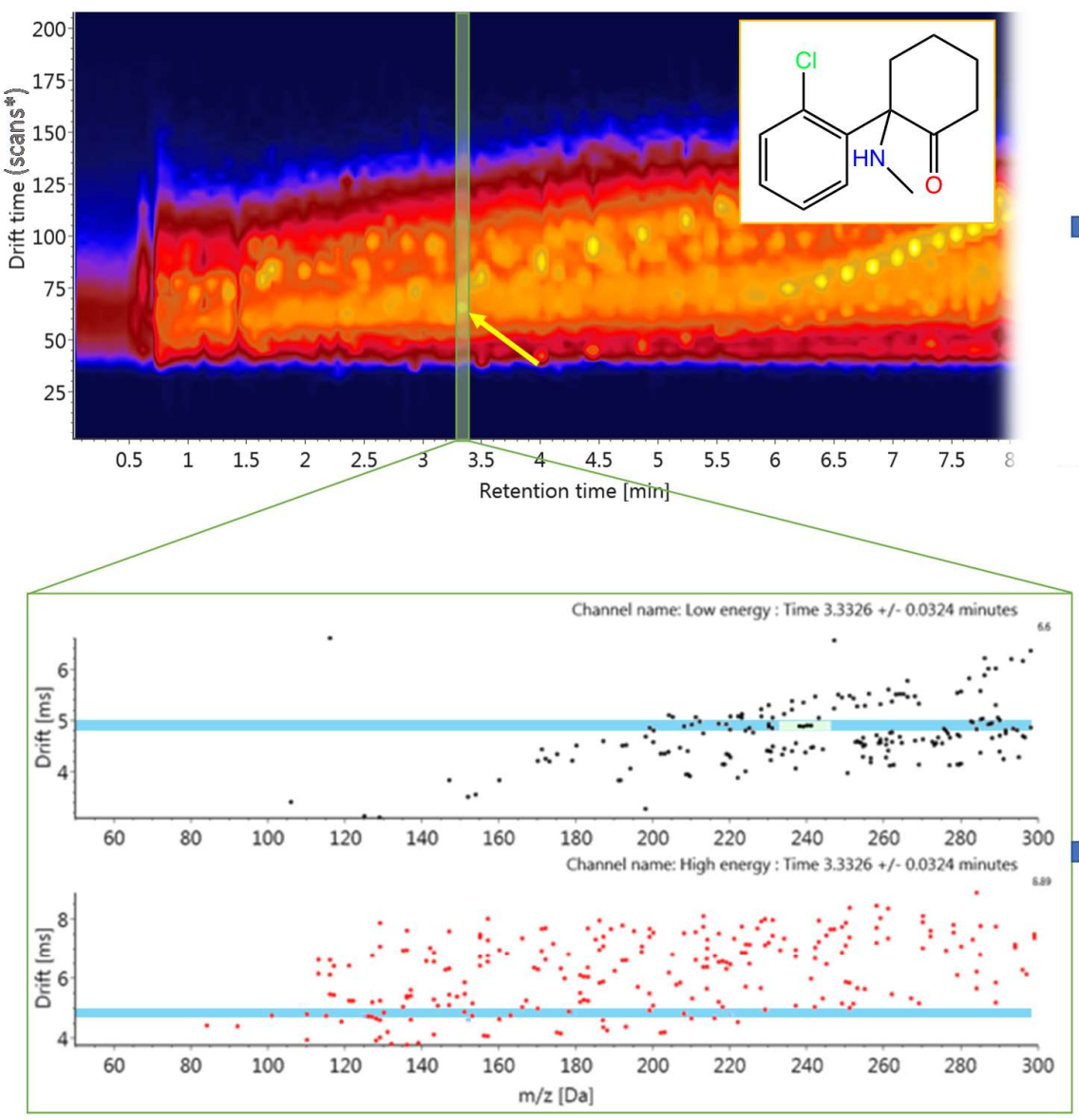

A

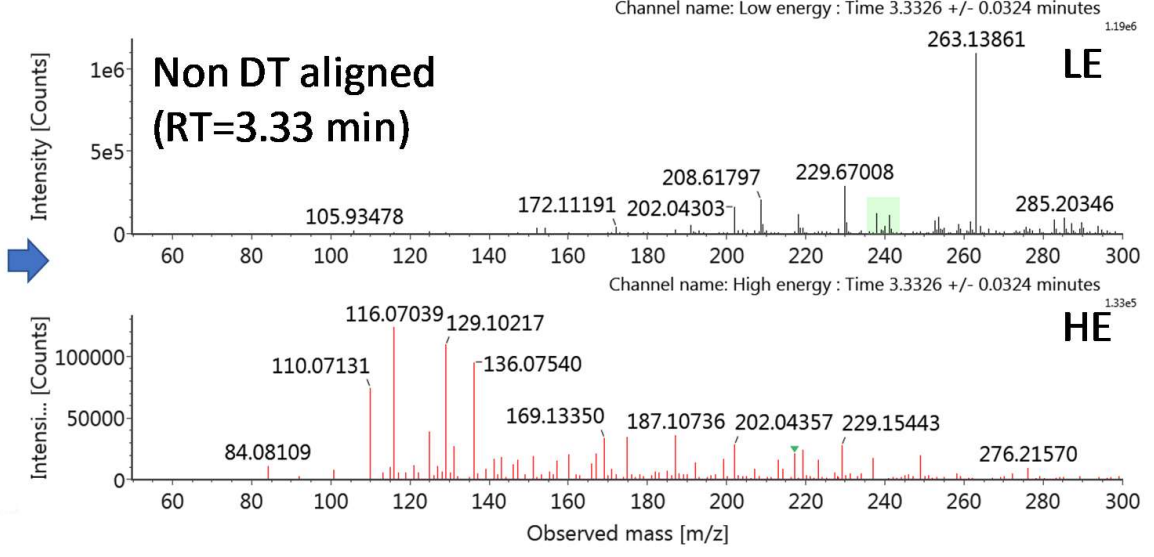

Channel name: Low energy : Time $3.3326+/-0.0324$ minutes : Drift Times: $4.89+/-0.20 \mathrm{~ms}$

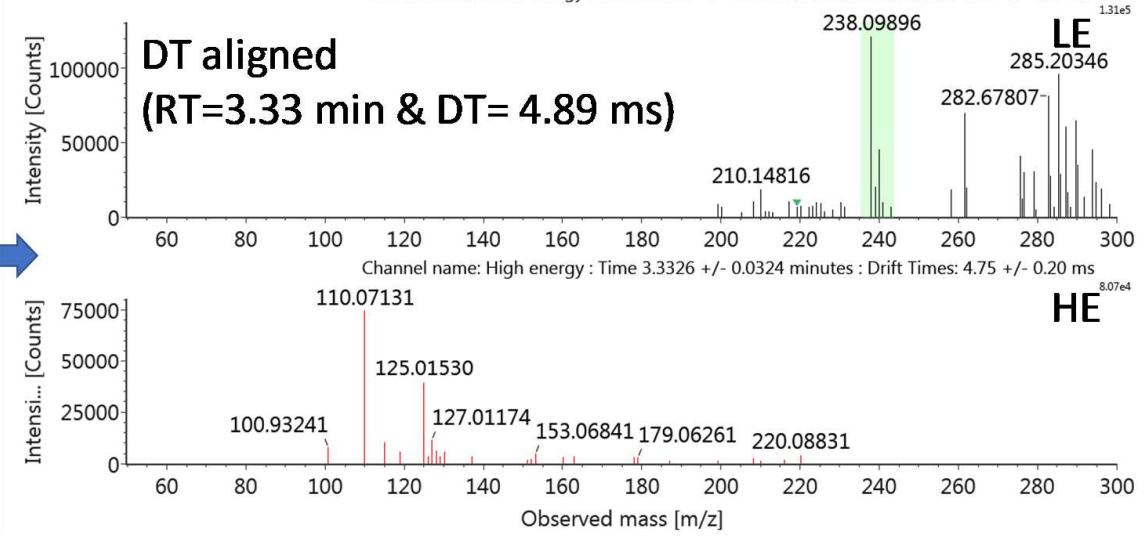

B 